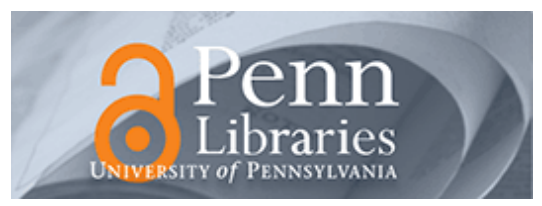

University of Pennsylvania

ScholarlyCommons

PSC Working Paper Series

$11-17-2014$

\title{
The Consequences of Abortion and Contraception Policies on Young Women's Reproductive Choices, Schooling and Labor Supply
}

Diego Amador

University of Pennsylvania, amadord@sas.upenn.edu

Follow this and additional works at: https://repository.upenn.edu/psc_working_papers

Part of the Demography, Population, and Ecology Commons, Maternal and Child Health Commons, and the Women's Health Commons

Amador, Diego, "The Consequences of Abortion and Contraception Policies on Young Women's Reproductive Choices, Schooling and Labor Supply" (2014). PSC Working Paper Series. 58.

https://repository.upenn.edu/psc_working_papers/58

Amador, Diego. 2014 "The Consequences of Abortion and Contraception Policies on Young Women's Reproductive Choices, Schooling and Labor Supply." PSC Working Paper Series, WPS 14-6. http://repository.upenn.edu/ psc_working_papers/58.

This paper is posted at ScholarlyCommons. https://repository.upenn.edu/psc_working_papers/58

For more information, please contact repository@pobox.upenn.edu. 


\title{
The Consequences of Abortion and Contraception Policies on Young Women's Reproductive Choices, Schooling and Labor Supply
}

\begin{abstract}
In this paper, I evaluate the effects of regulations that limit the availability of abortion services, as well as the impact of policies that subsidize contraception, on abortion and contraceptive choices of young women and on their life-cycle fertility, schooling and labor supply. I specify and structurally estimate a dynamic life-cycle model of abortion, contraceptive use, schooling and labor supply decisions using data from the NLSY97 combined with aggregate abortion provider data from the Guttmacher Institute. Variation across time and space in state-specific regulations and in the availability of abortion providers at the county level provides a valuable source of identification for the model parameters. My estimation approach allows for underreporting of abortions by NLSY respondents. Policy simulations show that restrictions on abortions increase contraceptive use, which moderates the effect of abortion restrictions on birth rates. Eliminating access to abortion services has significant effects on women's schooling and lifetime earnings. The average effect of restricting access to abortion on lifetime welfare is small, but there is substantial heterogeneity in welfare losses across women. As an alternative to abortion restrictions, I find that providing free contraception would increase contraceptive use and decrease abortion rates substantially.
\end{abstract}

\section{Keywords}

Abortion, Contraception, Fertility, Human Capital, Reproductive Health

\section{Disciplines}

Demography, Population, and Ecology | Maternal and Child Health | Medicine and Health Sciences | Social and Behavioral Sciences | Sociology | Women's Health

\section{Comments}

Amador, Diego. 2014 "The Consequences of Abortion and Contraception Policies on Young Women's Reproductive Choices, Schooling and Labor Supply." PSC Working Paper Series, WPS 14-6. http://repository.upenn.edu/psc_working_papers/58. 


\title{
The Consequences of Abortion and Contraception Policies on Young Women's Reproductive Choices, Schooling and Labor Supply*
}

\author{
Diego Amador ${ }^{\dagger}$ \\ University of Pennsylvania
}

\begin{abstract}
In this paper, I evaluate the effects of regulations that limit the availability of abortion services, as well as the impact of policies that subsidize contraception, on abortion and contraceptive choices of young women and on their life-cycle fertility, schooling and labor supply. I specify and structurally estimate a dynamic life-cycle model of abortion, contraceptive use, schooling and labor supply decisions using data from the NLSY97 combined with aggregate abortion provider data from the Guttmacher Institute. Variation across time and space in state-specific regulations and in the availability of abortion providers at the county level provides a valuable source of identification for the model parameters. My estimation approach allows for underreporting of abortions by NLSY respondents. Policy simulations show that restrictions on abortions increase contraceptive use, which moderates the effect of abortion restrictions on birth rates. Eliminating access to abortion services has significant effects on women's schooling and lifetime earnings. The average effect of restricting access to abortion on lifetime welfare is small, but there is substantial heterogeneity in welfare losses across women. As an alternative to abortion restrictions, I find that providing free contraception would increase contraceptive use and decrease abortion rates substantially.
\end{abstract}

Keywords: Abortion, Contraception, Fertility, Human Capital, Reproductive Health.

JEL classifications: J13, J16, J20

\footnotetext{
*This version, November 2014.

${ }^{\dagger}$ Department of Economics, University of Pennsylvania. amadord@sas.upenn.edu. I am immensely grateful to Kenneth Wolpin for his constant guidance and support and to Flavio Cunha and Petra Todd for all their time and valuable advice. I thank Hanming Fang, Holger Sieg, Nicolás Grau, Naoki Aizawa, Caroline Liu, Yumi Koh, Sina Ates, Ekimcem Muyan, Tzuo Hann Law and Fan Wang for very helpful comments. I also thank all the members of the Empirical Micro Group at the University of Pennsylvania for their always useful comments and suggestions. The Guttmacher Institute kindly allowed me to use their data on abortion providers. This research was also conducted with restricted access to Bureau of Labor Statistics data. The views expressed here do not necessarily reflect the views of Bureau of Labor Statistics or the Guttmacher Institute. This project was supported by the Eunice Shriver Kennedy National Institute of Child Health and Development Population Research Infrastructure Program R24 HD-044964-10, at the University of Pennsylvania. The content is solely the responsibility of the author and does not necessarily represent the official views of the University of Pennsylvania, the Eunice Shriver Kennedy National Institute of Child Health and Development or the National Institutes of Health.
} 


\section{Introduction}

Since the legalization of abortion in the United States in 1973 (Roe v. Wade), state and federal legislatures have enacted hundreds of laws imposing a wide range of requirements on abortion patients and providers. Prior studies show that demand-side restrictions significantly affect abortion rates, while laws targeted at abortion providers decrease the availability of abortion clinics. ${ }^{1}$ However, the effects of these restrictions may extend beyond abortion choices themselves. In the first place, women may also adjust their contraceptive use in response to these policies. Furthermore, if restrictions on abortions lead to changes in fertility, women's schooling and labor market choices may also be affected, as these decisions are known to be closely related to fertility. ${ }^{2}$ In this paper, I evaluate the long-run effects of regulations that limit the availability of abortion services, as well as policies that directly affect the price of contraception, on abortion and contraceptive choices of young women and on their life-cycle fertility, schooling and labor supply.

I proceed in three steps. First, I specify a dynamic life-cycle model of abortion, contraceptive use, schooling and labor supply decisions of women in the U.S. I then structurally estimate the parameters of the model by simulated maximum likelihood using data from the National Longitudinal Survey of Youth (NLSY97), combined with abortion provider data from the Guttmacher Institute (GI) and information on mandatory counseling laws enacted by several states during the sample period. Variation across time and space in these regulations and in the availability of abortion providers at the county level provides a valuable source of identification for the model parameters. In the estimation, I allow for underreporting of abortions by NLSY respondents and use aggregate abortion rates to identify the degree of bias in these abortion reports. Finally, I use the estimated model to simulate the effects of several counterfactual policies. I find that restrictions on abortions lead to a large increase in contraceptive use, which moderates the effect of abortion restrictions on birth rates and fertility. The counterfactual analysis shows that eliminating access to abortion services decreases accumulated schooling by $13 \%$ and lifetime earnings by $5 \%$ among women who would have ever had an abortion. The average effect on lifetime welfare is small, but there is substantial heterogeneity, and women at the right tail of the distribution suffer large losses in individual lifetime welfare. As an alternative to restrictive policies, providing free contraception increases contraceptive use by 12 percentage points, leading to a $38 \%$ decrease in the abortion rate for young women. ${ }^{3}$

In the model, raising children while working or attending school is costly. These costs, together with preferences for the number and timing of children, as well as preferences for the marital arrangement in which they are born and raised, generate incentives to control fertility. To do this, women in the model first decide on their contraceptive use. By using contraception, they lower, but do not eliminate, the chance of becoming pregnant. If a pregnancy occurs, they choose whether to obtain an abortion. Abortions entail both psychic and monetary costs. The psychic costs differ according to religiosity and may increase if the state in which they live imposes mandatory counseling restrictions. Women who choose an abortion and live in a county without an abortion provider need to travel to the nearest provider, which increases their monetary cost. In the labor market, women receive wage offers that depend on the current level of human capital. After knowing if they became pregnant, they decide whether to work part-time, full-time, or not

\footnotetext{
${ }^{1}$ Henshaw et al. (2009), Joyce et al. (2009), and Dennis et al. (2009) summarize the findings of the literature for Medicaid funding restrictions, mandatory counseling requirements and parental consent requirements, respectively. Beauchamp (2012) has shown that, between 1991 and 2005, supply-side regulation led to an annual average decrease of $5.86 \%$ in the number of counties with a provider.

${ }^{2}$ See, for example, Rosenszweig and Wolpin (1980), Moffit (1984), Hotz and Miller (1988), Angrist and Evans (1998), Francesconi (2002), Gayle and Miller (2006), Keane and Sauer (2009), Keane and Wolpin (2010), and Adda et al. (2012).

${ }^{3}$ For the purpose of analyzing abortion, contraceptive use, pregnancy and birth rates, I define young women as women ages 18 to 30 .
} 
work at all. At this time, they also choose whether to attend school. Both of these choices affect future wage offers, as human capital is accumulated through schooling and labor market experience. I make the simplifying assumption that marital status and sexual activity evolve according to an exogenous stochastic process. Finally, I allow for unobserved heterogeneity in preferences for abortions, schooling and leisure, in initial human capital, and in marital status and sexual activity profiles.

I use data from the NLSY97 and the Guttmacher Institute census of abortion providers. The NLSY97 follows a sample of women born between 1980 and 1984, interviewing them yearly starting in 1997. The sample period extends up to 2011 and includes women up to age 31. The data include detailed information on demographics, sexuality, contraceptive use, fertility, schooling, labor market participation and wages of the respondents. From the Guttmacher Institute census of abortion providers, I obtain information on the number of specialized and non-specialized abortion clinics in each county. These clinics account for $94 \%$ of all abortion procedures in the U.S. (Jones and Kooistra, 2011). I complement these data with publicly available information on the enactment of mandatory counseling/waiting period laws. The number of states with these kinds of restrictions increased from 12 to 25 during the sample period of the NLSY97. Thus, variation across time and space in these restrictions, as well as in the availability of clinics offering abortion services, provide useful information for the identification of the model parameters.

As documented for similar survey data (Jones and Kost, 2007), abortions are severely underreported in the NLSY97. In the estimation of the model, I address this key issue by specifying a biased measurement error process for abortions, pregnancies, miscarriages and births. ${ }^{4}$ I extend the simulated maximum likelihood estimation approach introduced by Keane and Wolpin (2001) and formalized by Keane and Sauer (2009) to incorporate information from aggregate abortion rates as a source of identification for the biased measurement error process. These aggregate abortion rates, which I obtain from the Centers for Disease Control and Prevention (CDC) and the Guttmacher Institute, do not suffer from underreporting, as they are calculated using abortion counts directly reported by abortion providers.

I use the estimated model to simulate the long-run effects of three types of policies on young women's abortion, contraceptive use, schooling and labor supply decisions and on their lifetime fertility, human capital accumulation and earnings. First, I consider the extreme case of a perfectly enforced ban on abortions, which provides an upper bound on the potential effects of abortion restrictions. This makes it possible to quantify the importance of the availability of abortion for contraceptive choices and for human capital accumulation through schooling and labor supply. Model simulations show that, as a consequence of this ban, the rate of contraceptive use for women ages 18 to 30 increases from $45.5 \%$ to $56 \%$. As a result, the number of pregnancies per 1000 women decreases from 137 to 118. The birth rate for this age group, on the other hand, increases from 88 to 107 births per 1000 women each year. ${ }^{5}$ Given that the abortion rate in the absence of this policy is 39 abortions per 1000 women, roughly one out of every two abortions is replaced by an additional birth. The restriction disproportionately affects single women, making the fraction of children born to single mothers increase from $25 \%$ to $30 \%$. With respect to human capital, the average amount of schooling accumulated after high school, 3.06 years in the absence of this policy, decreases by 0.15 years $(4.9 \%)$ and the fraction of women with a college degree drops by 2.3 percentage points. Moreover, among the women who would have ever had an abortion in the absence of the ban $-42 \%$ of the population-, the decrease in average schooling is 0.36 years $(13.2 \%)$, while the share of college graduates is 5.3 percentage points lower. On average, lifetime earnings decrease by $4.6 \%$ for this group of women. There is substantial

\footnotetext{
${ }^{4}$ Because abortions, pregnancies, miscarriages and births are not independent events, the underreporting of abortions biases the reports on these other variables as well.

${ }^{5}$ The remaining pregnancies result in a miscarriage.
} 
heterogeneity when calculating the individual lifetime welfare loss of eliminating abortion; $5 \%$ of women experience a loss equivalent to at least $6 \%$ of their lifetime welfare, while more than half experience no loss at all. Among women who would have ever had an abortion, $5 \%$ experience a loss larger than $10 \%$ of their individual lifetime welfare.

Second, I analyze the effects of two less extreme restrictions on abortions: the expansion of mandatory counseling laws and the closing of providers, a common consequence of laws targeted at abortion providers. With respect to mandatory counseling laws, expanding them to all of the states where they are not currently in place decreases the abortion rate for women ages 18 to 30 by 3.7 abortions per 1000 women, an $8.3 \%$ reduction. The pregnancy rate falls by 2.4 pregnancies per 1000 women as a consequence of a 1.4 percentage point increase in the use of contraception. Therefore, the birth rate increases by 1.2 births per 1000 women, which corresponds to $32 \%$ of the change in the number of abortions. Turning to the closing of providers, a large number of abortion clinics have recently closed, following the enactment of laws that impose strict requirements on doctors and facilities. A well-known example is a 2013 Texas law known as HB2. In October 2014, after all of the provisions of this law had gone into effect, only 7 of the 46 clinics present in Texas at the beginning of 2013 were still operating. ${ }^{6}$ I therefore examine the impact of these kinds of policies by assessing the effect that closing all of the providers in a county has on women living in that county. I find that, for the average woman living in a county that currently has an abortion provider, the abortion rate would decrease by $6.8 \%$ if all the providers in her county closed. This means that more than $93 \%$ of women who would have an abortion in the absence of this policy will now travel to a different county to obtain the abortion. Among those for whom the abortion choice changes as a result of the closing of providers, an increase in contraceptive use prevents the pregnancy in most cases and only $34 \%$ of them would have an additional birth. Therefore, in both of these cases - the expansion of mandatory counseling laws and the closing of providers-, the main effect of these restrictions on women who choose an abortion is to elevate the costs they face. Conditional on pregnancy, very few women who have abortions would choose to carry the pregnancy to term. Because the main mechanism through which abortion restrictions affect schooling and labor supply is through their effect on births, there would be no significant effects on human capital accumulation or labor market outcomes.

Finally, I evaluate the effects of a policy that fully subsidizes contraception as a potential alternative to reduce the abortion rate. Model simulations show that, when contraception is free, the rate of contraceptive use among young women is 13 percentage points higher, leading to a decrease in the pregnancy rate of 21.4 pregnancies per 1000 women (a 15.7\% decrease) and a decrease in the abortion rate of 14.7 abortions per 1000 women (a $38 \%$ decrease). For a group of women who can be characterized as non-college educated workers (based on the parameter estimates), this policy induces a substitution of labor supply from older ages to relatively younger ages, together with a $16 \%$ decrease in lifetime fertility.

This paper adds to a small set of studies that have specified models of abortion choice (Akerlof et al., 1996; Kane and Staiger, 1996; Kocharkov, 2012; Kennes and Knowles, 2013). In an influential theoretical paper, Akerlof, Yellen, and Katz (1996) (AYK) proposed a mechanism through which the introduction (legalization) of abortion could have changed norms surrounding marriage to explain the increase in out-of-wedlock births that has been observed in recent decades. Kennes and Knowles (2013) (KK) build on the interest of AYK and propose that the appearance of contraception and abortion could have decreased the value of marriage

\footnotetext{
${ }^{6} \mathrm{~A}$ week after the requirement that abortion providers meet the standards of ambulatory surgery centers went into effect in October 2014, the U.S. Supreme Court temporarily enjoined this provision while a federal Circuit Court evaluates the constitutionality of the law.
} 
by reducing the costs of sex outside of marriage. They calibrate their model to 1970 (before full legalization of abortion and open access to the contraceptive pill) and find that $60 \%$ of the changes in marital patterns and out of wedlock birth rates observed since 1970 can be explained by introducing abortion and access to the contraceptive pill in this context. Besides the focus on abortion itself, these two papers and my own share an interest in how changes in abortion and contraception regulation may have effects on other dimensions of women's lives. However, while AYK and KK focus on the marriage market, my paper focuses on the labor market, which is not included in their analysis. Moreover, this is the first paper that estimates a model of abortion choice.

I also contribute to a literature that has estimated models of contraceptive choice. Hotz and Miller (1988) estimated an econometric model of fertility and labor supply of married women in which fertility is imperfectly controlled through the use of contraception. Although they do not estimate a full behavioral model of these choices, their model can be interpreted as an approximation of a life-cycle model of labor force participation and contraceptive choice. It remains the only paper to estimate a model of contraceptive choice where the incentives to use contraception are tied to the labor market. ${ }^{7}$ Carro and Mira (2006) estimate a dynamic discrete choice model of contraceptive decisions of Spanish families over the life cycle. Their model shares several features with the contraceptive use aspect of my model. However, given their interest in explaining the life-cycle patterns of contraceptive choices, they ignore abortion decisions as well as any connection with the labor market. Delavande (2008) estimates a static model of contraceptive choice in which beliefs over the effectiveness of different methods are allowed to differ from actual effectiveness, showing the importance of these beliefs for women when choosing their contraceptive method. Unlike Delavande, I do not have data on expectations or beliefs, which prevents me from allowing for such differences in my model. Arcidiacono et al. (2012) estimate a dynamic discrete choice model of contraception and sexual activity among teenagers and show the importance of habit persistence for these decisions and the effect of policies related to contraception among teenagers. I have not included the sexual dimension as an endogenous variable in my model. As opposed to Arcidiacono et al. (2012), where sexual initiation is a crucial aspect of treating sexual activity as a choice, more than $75 \%$ of women in my sample are sexually active at the beginning of the modeling period. Moreover, it is not clear that a proper model of sexual activity choice (i.e., one with predictive power) could be developed in the context of this paper with the available data. Aside from Levine (2003), who finds that the reduction in pregnancies among minors as a consequence of parental consent laws comes from increased contraceptive use rather than changes in sexual activity, there is no empirical evidence to verify the restrictiveness of the exogeneity assumption. While previous studies have ignored the abortion decision when analyzing contraceptive choices, in this paper I consider the contraceptive choice together with the abortion decision. This allows me to quantify the extent to which contraceptive choices are affected when abortion costs change and vice-versa. Furthermore, when analyzing contraceptive and abortion choices, I consider their relationship with labor supply and schooling choices, explicitly taking into account crucial incentives for the use of abortion and contraception. Thus, I am able to quantify the effects of restrictions on abortions on human capital accumulation through schooling and labor market experience.

Finally, this paper contributes to a large literature in demography and economics which has estimated the effects of changes in abortion regulation and policies related to access to contraception on abortion rates, birth rates and, in very few cases, on contraceptive use. Some of these studies relate to policies that I evaluate in this paper. For instance, Joyce et al. (1997) and Joyce and Kaestner (2000) study the short-

\footnotetext{
${ }^{7}$ It is worth noting that Hotz and Miller (1993) also estimated a contraceptive choice model in their seminal paper, although it is only used as an example for the implementation of the method they proposed for the estimation of dynamic discrete choice models.
} 
run effects of the introduction of a mandatory counseling and waiting period law in Mississippi. The key findings from this set of papers are that the law decreased the abortion rate by $10 \%$ while increasing the proportion of second trimester abortions and the mean gestational age at the time of abortion. Although the populations to which these results and mine apply are different, the magnitude of these effects is consistent with my findings. I contribute to the analysis of mandatory counseling and waiting period laws by analyzing their effect in states where they have not been implemented and by assessing their impact on contraceptive choices, birth rates, fertility and human capital accumulation. Kearney and Levine (2009) study the effects of Medicaid waivers which expanded Medicaid coverage of family planning services in many states. Their research relates to the contraception subsidy that I evaluate. They find that waivers that raised the income threshold to receive family planning services had a strong impact on contraceptive use and birth rates, which are consistent with my results. However, given the data they use, they are unable to conclude whether these policies had any effects on abortion decisions. Joyce et al. (2012) analyze the effect of distance to New York on abortion decisions during the years immediately before Roe v. Wade, when abortion was legal in New York State but not in most of the U.S. Their results highlight the importance of local availability of providers for abortion decisions. As mentioned, these studies relate to policies that I analyze in this paper. Thus, in Section 6, I discuss in more detail how their results relate to mine. The literature has also studied two kinds of demand-side restrictions that are not directly related to the policies I evaluate: parental consent restrictions for minors and funding restrictions for Medicaid members. Their findings are worth noting here, as they present strong evidence of the impact that restrictions in general have on abortion decisions. Joyce et al. (2006) and Colman and Joyce (2009) use administrative data from Texas to analyze the effect of the introduction of a parental consent requirement for minors in that state on abortion rates and on the fraction of second trimester abortions. When comparing abortion rates for women at both sides of the age threshold that defines whether parental consent is required (18 years), they find that the abortion rate decreased by $16 \%$ and the rate of second trimester abortions increased by $21 \%$ for those for whom parental consent is required, relative to those for which it is not. In North Carolina, the budget allocated to pay for abortions for Medicaid members has been exhausted before the end of the year on several occasions. The lack of funding for Medicaid abortions induced by this event has been used as a natural experiment to estimate the short-run effects of changes in funding on abortion decisions. For instance, Cook et al. (1999) find that, among eligible women, $37 \%$ of the pregnancies that would have ended in abortion were carried to term, a result that is consistent with the later analysis of Morgan and Parnell (2002). Finally, with respect to the supply-side restrictions, Beauchamp (2012) estimates a dynamic model of entry and exit of providers to the abortion market. He finds that restrictions imposed on providers lead to the concentration of abortion services in fewer and bigger abortion clinics, decreasing the number of providers and thus access to abortion services. As all of these studies show, there is strong evidence that the regulations that have been imposed since Roe $v$. Wade have relevant effects on abortion decisions directly, as well as indirectly through their effect on the availability of providers. This supports the importance of analyzing the effect of further restrictions. The evaluation of the perfectly enforced ban on abortions - the strictest restriction possible- is particularly important as the number and variety of restrictions accumulates and legislatures discuss increasingly restrictive regulations. I contribute to this broad literature by developing a framework to analyze these counterfactual policies, quantifying the effect of abortion policies on contraceptive use, and assessing their potential effects on schooling and labor supply decisions.

The rest of this paper is organized as follows. I provide a description of the context of abortion and contraceptive use in the United States in Section 2. I then present the model in Section 3. Next, in Section 
4, I describe the data. Section 5 describes the estimation method and the way in which I address the underreporting of abortions in the data. Results can be found in section 6 . In section 7 , I conclude.

\section{Background}

\subsection{Legal context}

In this section I provide a brief summary of the recent history of abortion regulation in the U.S. to describe the context in which the choices studied in this paper are made, focusing on certain restrictions that are crucial to this analysis. The behavioral model in section 3 represents decisions made in this particular environment.

Up until 1967, abortion was illegal in most cases for all of the states of the U.S. It was generally allowed if carrying the pregnancy to term would put the mother's life at risk. Some states allowed it in cases of rape as well. Between 1967 and 1973, some states started allowing abortions under a slightly larger array of circumstances, following the guidelines established in a 1962 proposal by the American Law Institute. Meanwhile, four states - New York, Alaska, Washington, and Hawaii - repealed the laws prohibiting abortions, making it legal to obtain abortions in these states. In 1973, the Supreme Court ruled that abortion was protected by the legal right to privacy under the U.S. Constitution (Roe v. Wade). As a consequence of this, nobody in the U.S. can be prosecuted for seeking or providing an abortion, subject to some restrictions on the maximum gestational age at which abortions can be performed. Roe $v$. Wade acknowledges a legitimate interest of the State on the life of the fetus as gestation increases. Therefore, individual states are allowed to have specific regulations as long as these do not impose an "excessive burden" on women seeking an abortion. However, what has been considered to be "excessive burden" has varied over time.

In 1976, the Hyde Amendment was approved by U.S. Congress. This law excludes abortion services from the set of services that can be covered by Federal health provision. In practice, this means that Federal funds cannot be used to perform abortions for Medicaid members. Individual states can, nevertheless, use their own funds. Today, 17 states use their own funds to finance abortions for Medicaid women (Jones et al., 2010).

In 1992, the Supreme Court ruled on the constitutionality of five regulations imposed by the 1982 Pennsylvania Abortion Control Act (Casey v. Planned Parenthood). Although the requirement of spousal notification for married women was struck down, the Court upheld the other four regulations: the requirement that doctors inform women about the health consequences of obtaining an abortion, the mandate of a 24 hour waiting period after this information was provided, the requirement that minors obtain consent from a parent or legal guardian, and a series of reporting mandates imposed on abortion providers. As a consequence of this ruling, many states imposed similar restrictions in the years to follow. Moreover, because Casey v. Planned Parenthood did not consider these restrictions to impose "excessive burden", this ruling opened the door for new restrictions to be imposed by state laws.

Demand-side restrictions that have been imposed generally fall into one of the following categories: mandatory counseling and waiting periods, parental consent/notification for minors, Medicaid bans, ultrasound requirements, or health insurance bans. As of 2014, 26 states require counseling and waiting periods; 39 require either notification or consent of parents or legal guardians for minors seeking to obtain an abortion; 8 states do not allow private health insurance plans to cover the costs of abortions except when the woman's life is in danger and 25 (including the previous 8) restrict coverage for health insurance plans offered through 
the exchanges created by the Affordable Care Act; 3 states require that an ultrasound be performed and showed to each abortion patient; and 9 require the ultrasound be performed and the woman be given the option of watching it.

Despite this large variation in policies, only mandatory counseling/waiting period restrictions and Medicaid bans provide variation that could potentially be used to estimate the model in this paper. Because I focus on young adults, minor consent requirements are not binding. Health insurance bans are not frequent enough, as they were present only in 5 states by 2011, the last year for which I have data. Most ultrasound requirements have been imposed over the last couple of years as well.

The timing of mandatory counseling and waiting periods restrictions offers very useful variation for estimation. In 1997, when NLSY97 data collection began, only 12 states had imposed this kind of restrictions; by 2011, the last year in the sample period, this number had increased to 25 . Thus, variation across space and time can be used in the estimation. On the other hand, there has been no policy variation in Medicaid funding of abortions since 1997. Thus, only variation between states could be exploited. From the 26 states that currently have mandatory counseling restrictions, 23 also have Medicaid bans. Thus, it is difficult to identify any effect of Medicaid bans separately. Moreover, including Medicaid in the model would require explicitly modeling the different rules for eligibility across states and time, making assumptions on how women form expectations about the changes in Medicaid eligibility rules, and including the Medicaid enrollment decision in the model. Given the little variation that can be exploited, modeling Medicaid would over-complicate the model without adding much to the estimation. Thus, I restrict my attention to women who are high school graduates in an attempt to reduce the number of women in my sample whose decisions could be influenced by this policy variation.

The counseling and waiting period restrictions vary from one state to another but follow the same general form. A pre-determined set of information needs to be provided to any woman seeking an abortion in a mandatory counseling session. Then, a pre-specified amount of time needs to go by between this session and when the abortion procedure is performed. Some states require that women obtaining abortions receive some basic information on the risks prior to the procedure, while others require a much more detailed set of information. In several cases, this information is either medically inaccurate or is not related at all to risks or consequences of the procedure and thus is medically unnecessary. In some cases, the information can be provided by staff members over the phone, while in the most restrictive cases the information must be provided in person and at least 24 hours prior to the procedure. In those cases, women seeking abortions need to make two different visits to the medical facility.

Besides these demand-side restrictions, many laws impose requirements on the doctors performing the abortions, the type of procedures that can be used and physical requirements for facilities of abortion providers. Some other laws limit the type of methods that can be used. Many of these laws, especially the ones imposing requirements on doctors and providers, are particularly restrictive as these provisions are difficult to fulfill for many abortion clinics, thus forcing many of them to close. ${ }^{8}$ Therefore, the effects of these laws on abortion decisions can be captured by their indirect effect through the changes they induce on provider availability and access to services.

\footnotetext{
${ }^{8}$ These laws, especially in their most recent and restrictive versions, are referred to as Targeted Restrictions on Abortion Providers or TRAP laws.
} 


\subsection{Access to abortion services}

In $2011,89 \%$ of the counties in the U.S. did not have an abortion provider, although only $38 \%$ of women ages 15 to 44 lived in these counties. These figures, however, display substantial regional variation. While $94 \%$ of counties in the Midwest didn't have an abortion provider in 2011, only $65 \%$ didn't have one in the Northeast. There were 225 providers in New York State in 2011. This number was four times as large as the one for Texas in that year (Jones and Jerman, 2014). ${ }^{9}$

Abortions typically take place in clinics specializing in abortions (70\%) and other non-specialized clinics $(24 \%) .{ }^{10}$. $94 \%$ of the abortions in 2008 (92\% in 2011) were performed by providers that handle 400 cases or more each year (Jones and Kooistra, 2011; Jones and Jerman, 2014) I will include information on the location of these providers in the estimation, as will be described in Section 4. Any effect of supply side restrictions will be captured in the estimation through its effect on the availability of providers at the county level.

\subsection{Abortion patients}

Figure 1 shows the evolution of the abortion rate in the U.S. from 1973 to 2011. Following Roe v. Wade, the abortion rate in the U.S rose steadily and peaked around 1981 when it reached almost 30 abortions per 1000 women. The rate has declined ever since, reaching a low of 16.9 abortions per 1000 women in 2011. The pregnancy rate (not shown) has followed a similar trend but with a slightly less steep decline. As of $2011,21.2 \%$ of pregnancies ended in abortions. ${ }^{11} 12$

Table 1 divides U.S. women age 15-44 according to different socio-demographic characteristics and presents the share of the total number of abortions coming from each group (column 1) and the number of abortions per 1000 women in that group (column 2). In this way, column 1 provides information on the groups that account for the largest part of the total number of abortions. From an aggregate point of view, these are the women that drive the trends in abortion rates. The abortion rates in column 2, on the other hand, show the probability of getting an abortion conditional on being in that group. They thus provide information on the characteristics more closely correlated with abortion decisions.

In terms of the share, women ages 18-34 account for over $82 \%$ of the abortions in the U.S. with almost $70 \%$ coming from women 18-30, which is the age group in the data I use to estimate the model. Also, $87 \%$ of the procedures involved women with at least a high school degree or GED. As mentioned earlier, these are the women I use for the estimation in this paper and thus they are the ones for which any results apply. Finally, in terms of marital status, only $15 \%$ of abortion patients are married women. On the other hand, $30 \%$ come from women in cohabiting relationships, despite the fact that less than $10 \%$ of the women ages 15-44 belong to this group.

Cohabitation is also very strongly correlated with the decision to get an abortion: the abortion rate for women in this type of relationship is 52 abortions per 1000 women. Married women, on the other hand, have an extremely low abortion rate of only 6.6 abortions per 1000 women. The abortion rates are practically the same for all education groups - around 22 abortions per 1000 women - except for college graduates, who have a lower abortion rate. Not surprisingly, the abortion rates are higher for age groups that are more fecund. The rates are above the average for women 18-29, with the highest abortion rate being that of

\footnotetext{
${ }^{9}$ The number of providers has decreased dramatically in Texas since 2011, the last year in the sample period I use in the estimation.

${ }^{10}$ These shares are for 2008.

${ }^{11} 2011$ is the last year for which an official pregnancy rate is available.

${ }^{12}$ This fraction counts only abortions and pregnancies ending in live births.
} 
Figure 1: Abortion rate U.S. 1973-2011.

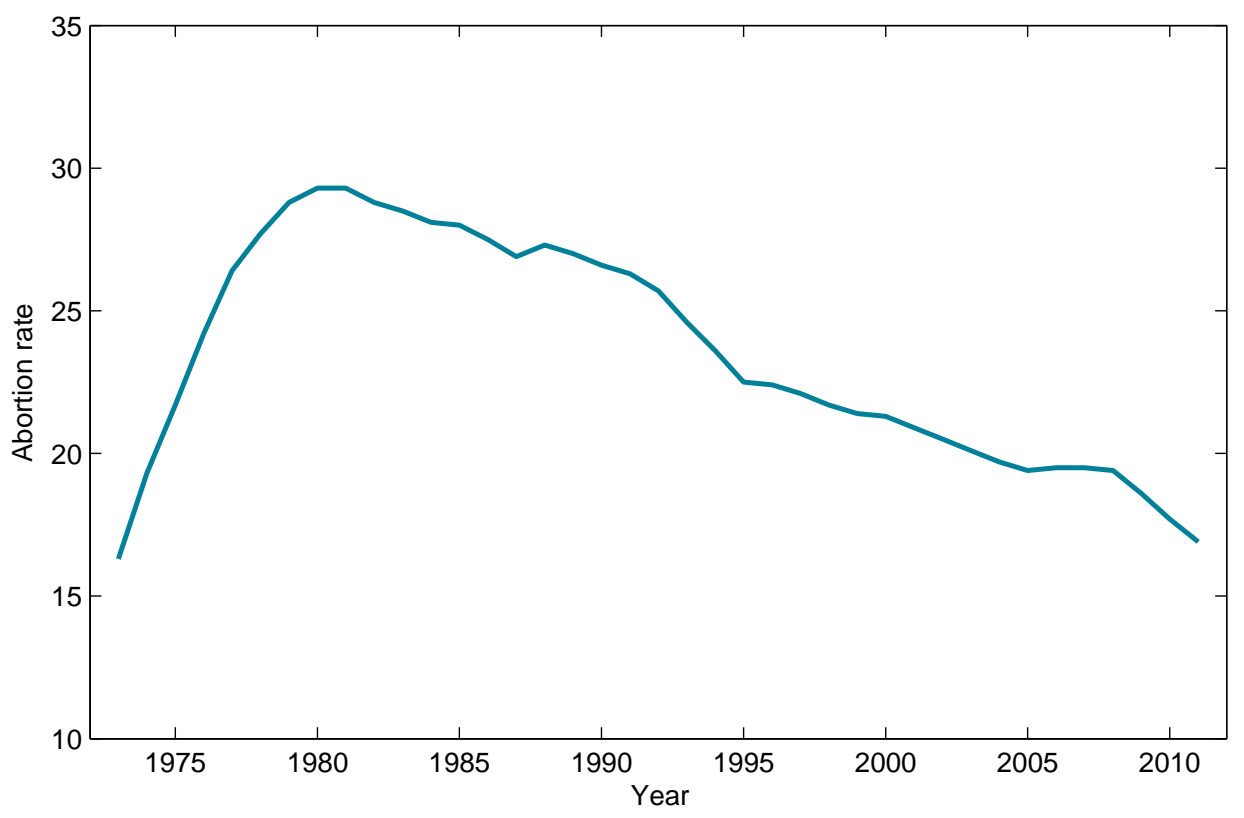

Abortion rate is the number of abortions per 1000 women age 15-44. Source: Guttmacher Institute.

women 20-24 years old. There are also important differences in terms of race: abortion rates are the highest for (non-hispanic) black women (40.2), followed by hispanic women (28.7). The rate for white non-hispanic women is the lowest.

There is substantial variation in terms of the fraction of abortions in a particular state that come from women who are residents of another state. This fraction goes from 0 in Wyoming (where there are less than 1000 abortions per year and none of the 3 providers are specialized clinics) to $54 \%$ in Washington D.C. (Pazol et al., 2011). This suggests that a large number of women travel to get abortions in a different place than where they live, plausibly due, at least in part, to the absence of abortion providers where they reside. This is consistent with the importance of the distance and local availability of abortion providers that Joyce et al. (2012) found for women's abortion decisions around the time of the legalization of abortion.

Finally, in terms of the payments for abortion procedures, nearly $60 \%$ of the women who get abortions pay for the full cost of the procedure out-of-pocket. Only $20 \%$ of the procedures are paid for by Medicaid (Jones et al., 2010). Finally, it is worth noting that $54 \%$ of the women who got abortions in 2008 reported that they had been using a contraceptive method at the time of the pregnancy. $38 \%$ said they were not using one at the time but had used a contraceptive method in the past. Only $8 \%$ reported they had never used any contraceptive method (Jones et al., 2010).

\subsection{Contraceptive use}

Table 2 shows usage rates for different contraceptive methods by age, as reported in the National Survey of Family Growth 2006 - 2008. (Mosher and Jones, 2010). Even though these numbers come from cross sectional data, they suggest a life cycle pattern of substitution of transitory methods for permanent ones. They also show how the contraceptive pill and condom are the most preferred methods. These patterns 
motivate the definition of contraceptive method options in the model, as it is described in the next section.

Table 1: Abortions by socio-demographic characteristics. 2008.

\begin{tabular}{|c|c|c|}
\hline Age & $\%$ & Rate \\
\hline $15-17$ & 6.2 & 11.3 \\
\hline $18-19$ & 11 & 34.7 \\
\hline $20-24$ & 33.4 & 39.9 \\
\hline $25-29$ & 24.4 & 28.6 \\
\hline $30-34$ & 13.5 & 17.1 \\
\hline $35-39$ & 8.2 & 9.3 \\
\hline$>39$ & 2.9 & 3.2 \\
\hline
\end{tabular}

\section{Education}

$<$ High School

High School/GED

Some college/ Associate degree

College or more

\section{Union Status}

Married

Cohabiting

Never married, not cohabiting

Previously married, not cohabiting

$11 \quad 25.6$

\section{Race}

Non hispanic white

The first column shows the fraction of abortions corresponding to each group. Abortion rate: number of abortions per 1000 women in each group.

Source: Jones et al. (2010) and Jones and Kavanaugh (2011) based on GI 2008 census of abortion providers.

\section{Model}

To answer the questions that guide this research, I develop a discrete choice dynamic programming model of abortion, contraceptive, labor supply, and schooling decisions over the life cycle. In this section, I present the basic structure of the model. Because one of the main goals of this paper is to perform counterfactual policy experiments, the model includes many components intended to capture the facts and correlations described in section 2. With few exceptions, I do not explicitly present here the functional form or distributional assumptions for the different elements in the model. I refer the reader to the Appendix A for details. 
Table 2: contraceptive use and method by age (\%). 2006-208

\begin{tabular}{cccccc}
\hline & Using & \multicolumn{4}{c}{ Method used (if using) } \\
\cline { 3 - 6 } Age & contraception & Pill & Condom & Sterilization & All other \\
\hline $15-19$ & 28.2 & 54.1 & 22.8 & 0.0 & 23.1 \\
$20-24$ & 54.7 & 48.0 & 24.5 & 3.1 & 24.4 \\
$25-29$ & 64.2 & 35.1 & 20.5 & 18.3 & 26.1 \\
$30-34$ & 70.3 & 24.8 & 17.1 & 37.6 & 20.5 \\
$35-39$ & 75.0 & 19.3 & 11.2 & 54.1 & 15.4 \\
$40-44$ & 77.8 & 11.1 & 8.8 & 69.8 & 10.3 \\
\hline
\end{tabular}

Source: Mosher and Jones (2010) based on NSFG data (2006-2008)

Sterilization includes male and female sterilization.

\subsection{Environment and choice set}

The agents in the model are women who are high school graduates. ${ }^{13}$ A period is a year and time is indexed in terms of the individual's age. In each period, starting from the age at which they leave high school, $\underline{a_{i}}$, until the deterministic retirement age $A=65$, they make four choices:

- Labor supply, which can be full time work $\left(h^{f} \in\{0,1\}\right)$, part time work ( $\left.h^{p} \in\{0,1\}\right)$, or not participating in the labor market. $\mathbf{h}$ is a vector that contains the indicators $h^{p}$ and $h^{f}$.

- School attendance for college or graduate school $(s \in\{0,1\})$.

- Which contraceptive method to use, if any. The variables $d b c^{k} \in\{0,1\}$ indicate that method $k$ is chosen. The vector bc contains all these indicator variables.

- Whether to get an abortion or not $(a b \in\{0,1\})$ if a pregnancy occurs.

I assume schooling choices are only made until age 30. Pregnancies can only occur until age 44, and thus the contraceptive method and abortion decisions are only made until that age.

There are two different decision stages within each period. A woman first makes a contraceptive method choice. After knowing if she has become pregnant or not, she decides on school attendance, labor supply, and whether to get an abortion or not (if she is pregnant). It is thus convenient to separate the decisions into two groups according to their timing: the birth control choice, indexed by $k$, and the mutually exclusive combinations of other alternatives, indexed by $j$.

Finally, in each period a woman can be either married, cohabiting, or single. I make the strong simplifying assumption that this marital status is not a choice and thus evolves over time according to an exogenous stochastic process.

\subsection{Preferences}

At each age, a woman receives flow utility $U_{a}$ given by:

$$
U_{a}=U\left(C_{a}, \mathbf{N}_{a}, f_{a}, \mathbf{h}_{a}, s_{a}, \mathbf{b c}_{a}, a b_{a} ; \boldsymbol{\eta}_{a}, \boldsymbol{\nu}_{a}, \text { type }, \boldsymbol{\Omega}_{a}\right)
$$

Where $C$ is consumption; $\mathbf{N}$ is a vector containing the number of children in different age groups; and $s$, $\mathbf{h}$, bc, and $a b$ indicate the choices described earlier. $f$ takes the value of 1 if a pregnancy occurs and 0 otherwise. $\boldsymbol{\nu}$ is a vector of preference shocks for contraceptive methods, $\boldsymbol{\eta}$ is a vector of preference shocks for all other choices, and $\boldsymbol{\Omega}_{\boldsymbol{a}}$ represents the state space. Finally, type refers to unobserved (in the data) types

\footnotetext{
${ }^{13}$ In the empirical implementation, women with a GED are counted as high school graduates.
} 
of women, which differ in their preferences over some of the arguments in $U(\cdot)$, as I will describe in more detail later.

To make the solution and estimation of the model feasible in terms of computation time, I assume $U$ can be written as:

$$
U_{a}=C_{a}+g\left(\mathbf{N}_{a}, f_{a}, \mathbf{h}_{a}, s_{a}, a b_{a} ; \boldsymbol{\eta}_{a}, t y p e, \boldsymbol{\Omega}_{a}\right)+e\left(\mathbf{b c}_{a} ; \boldsymbol{\nu}_{a}, \boldsymbol{\Omega}_{a}\right)
$$

\subsection{Budget constraint}

Given the linearity assumption with respect to consumption in the utility function, a woman's consumption is equal to her income, net of expenditures in schooling, contraception, and abortion services. Her income is composed by her earnings, if she is single, or a fraction $\tau^{h}$ of her husband's/partner's and her earnings combined, when married or cohabiting. ${ }^{14} 15$

$$
\begin{aligned}
C_{a}= & \left(1-d m_{a}\right) y_{a}^{w}+d m_{a} \tau^{h}\left(y_{a}^{w}+y_{a}^{h}\right) \\
& -s_{a}\left(T^{c o l l} I\left\{S_{a}<16\right\}+T^{g r a d} I\left\{S_{a} \geq 16\right\}\right)-\kappa_{a} a b_{a}-\sum_{k=1}^{K} d b c_{a}^{k} c_{k}^{b c}
\end{aligned}
$$

$T^{\text {coll }}$ and $T^{\text {grad }}$ are college and graduate school tuition, respectively. $\kappa$ is the cost of an abortion. $c_{k}^{b c}$ are the monetary costs of the different contraceptive methods. $y^{w}$ are the woman's earnings and $y^{h}$ are her husband's earnings. $d m$ is a variable that indicates if the woman is either married or cohabiting $(d m=1)$, or single $(d m=0)$.

\subsection{Wages, labor supply and schooling}

The labor market is perfectly competitive. At the beginning of each period, a woman receives wage offers and decides whether to work part-time, full-time, or not work at all. The wage offers are given by:

$$
w_{a}^{o}=r^{o} \Lambda_{a}\left(S_{a}, H_{a}, \text { type }, \varepsilon_{a}\right)
$$

where $r^{o}$ is the rental price of human capital, which is different for part-time $(o=p)$ and full-time $(o=f)$ jobs. $\Lambda$ is human capital, which is accumulated through schooling $S_{a}$ and labor market experience $H_{a}$ and is subject to an i.i.d. random shock $\varepsilon_{a}$ in each period. The initial human capital endowment is type-specific. Schooling at age $a$ is given by:

$$
S_{a}=12+\sum_{\tau=\underline{a}}^{a-1} s_{\tau}
$$

where I have assumed high school is equivalent to 12 years of school. Labor market experience is measured in thousands of hours worked after high school. I assume part-time work is one thousand hours per year and full-time work is two thousand hours in a year. Thus:

\footnotetext{
${ }^{14}$ For simplicity, from now on I will refer to both the husband, when married, and the partner, when cohabiting, as husband.

${ }^{15} I\{\cdot\}$ is an indicator function that takes the value of 1 if the argument is true and 0 otherwise.
} 


$$
H_{a}=\sum_{\tau=\underline{a}}^{a-1}\left(h_{\tau}^{p}+2 h_{\tau}^{f}\right)
$$

Given the wage offers and labor supply choices, earnings are then given by (in thousands of dollars):

$$
y_{a}^{w}=h_{a}^{p} w_{a}^{p}+2 h_{a}^{f} w_{a}^{f}
$$

\subsection{Contraceptive choices, pregnancies and abortions}

In each period, a woman first chooses which contraceptive method to use. Even though the number of actual options available to a woman is quite large, I simplify this decision to allow for only three options: not using any contraception $(k=0)$, using a "standard" transitory contraceptive method $(k=1)$, or choosing permanent sterilization $(k=2)$. Each of the two actual contraceptive methods $(k>0)$ is associated with a monetary $\operatorname{cost} c_{k}^{b c}$ and a utility cost $e_{k}$, which appeared in equations (2) and (1). The latter represents things like going to doctor's appointments, going through the procedure, making the trip to the pharmacy, getting the prescription renewed, the pure dissatisfaction of using the method, side effects, partner's preferences over the method, and any other costly activities related to acquiring or using the particular contraceptive method. Both $c_{0}^{b c}$ and $e_{0}$ are normalized to zero.

Choosing sterilization prevents pregnancies perfectly and is irreversible, eliminating the possibility of having children in any future periods. The probability that a woman becomes pregnant if sterilization has not been chosen is given by:

$$
\Pi_{a}=\Pi\left(\mathbf{b c}_{a}, S_{a}, S X_{a}, a\right)
$$

Thus, the standard contraceptive method affects the probability of becoming pregnant without eliminating it altogether. Aside from the contraceptive choice, the probability that a woman becomes pregnant during is a function of her age, schooling, and level of sexual activity $(S X)$, which I will describe in more detail later. This function $\Pi$ captures what is known as "typical use" effectiveness of contraception, i.e. the probability of becoming pregnant when contraception is used as it is normally used rather than following the instructions perfectly. Thus, the inclusion of schooling as an argument allows for differences by education in how well contraception is used.

If a pregnancy occurs $(f=1)$, a woman decides whether to get an abortion or not $(a b)$. Getting an abortion requires paying monetary and psychic (utility) costs. The monetary cost is composed of the out of pocket price and the costs incurred by a woman when she needs to travel to obtain an abortion if she does not live in a county with an abortion provider $(l o c)$ :

$$
\kappa_{a}=\kappa_{0}+\kappa_{1}\left(1-l o c_{a}\right)
$$

Each woman has an idiosyncratic time-invariant psychic cost of abortion $\xi$ which is drawn from a distribution with a mean that is allowed to differ by type and religiosity.

$$
\log (\xi) \sim N\left(\mu_{\xi}(\text { rel, type }), \sigma_{\xi}^{2}\right)
$$

If a woman resides in a state where there are mandatory counseling laws $\left(r e g_{a}\right)$, her psychic costs increase by an amount $\chi$, which captures the burden imposed by these restrictions. 
Finally, miscarriages may occur after the abortion decision has been made. Thus, if a pregnant woman decides to carry on with her pregnancy, a child will be born in the next period with probability $q^{M C}-$ miscarriages $(m c)$ occur with probability $\left(1-q^{M C}\right)$. The contraceptive and abortion decisions, together with the pregnancy and miscarriage outcomes, determine the evolution of three key state variables: the presence of a new born child $(n)$, the number of children between the ages of 1 and $5\left(N^{5}\right)$, and the number of children between the ages of 6 and $17\left(N^{17}\right)$.

$$
\begin{aligned}
& n_{a+1}=f_{a}\left(1-a b_{a}\right)\left(1-m c_{a}\right) \\
& N_{a+1}^{5}=\sum_{\tau=a-5}^{a-1} n_{\tau} \\
& N_{a+1}^{17}=\sum_{\tau=a-17}^{a-6} n_{\tau}
\end{aligned}
$$

I assume children age 18 and older have no effect on the decisions in the model.

\subsection{Exogenous state variables}

Local conditions There are two state variables that summarize the local conditions that affect the costs faced by a woman when obtaining an abortion: if there is a provider in the county in which she lives (loc) and if the state in which she lives imposes mandatory counseling and waiting period laws (reg). I assume that $l o c$ evolves according to a markov processes $q^{l o c}$. With respect to reg, I assume there are two types of states: states that may impose these laws and and states that never impose these laws. I do this to correctly represent the data. Thus $\mathrm{reg}_{a}$ indicates if the state in which the woman lives has mandatory counseling restrictions at that time, while regtype indicates the if the state is of the type that imposes or may impose these restrictions in the future. For states that may impose these restrictions but have not done so by the current period, the probability that they will impose mandatory counseling restriction in the next period is given by $P\left(\right.$ reg $g_{a+1}=1 \mid$ reg $_{a}=0$, regtype $\left.=1\right)=q^{r e g}$. To correctly represent the data, I also assume that $r e g=1$ is an absorbing state.

Marital Status There are three possible marital status in the model: single, cohabiting and married. As mentioned earlier, I assume that the transitions between these states are exogenous. At the beginning of

each period, the woman is revealed her marital status. The probability distribution over the three possible marital status at age $a+1$ is a function of a subset of the state space variables:

$$
P\left(M_{a+1} \mid \Omega_{a}\right)=q^{M}\left(a, M_{a}, \operatorname{dur}\left(M_{a}\right), S_{a}, s_{a} . t y p e\right)
$$

where $\operatorname{dur}\left(M_{a}\right)$ is the amount of time accumulated in the current marital status. Husbands provide income to the household, which follows an exogenous process:

$$
y_{a}^{h}=y^{h}\left(a, \varphi_{a}, \varepsilon_{a}^{h}\right)
$$

In the first period when she becomes married or cohabiting after being single, the woman draws her husband's permanent component of earnings $(\varphi)$, which remains constant as long as the relationship survives (i.e. as long as she remains cohabiting or married). The mean of the distribution from which $\varphi$ is drawn 
depends on the woman's schooling and type: ${ }^{16}$

$$
\varphi_{a} \sim N\left(\mu_{\varphi}\left(S_{a}, \text { type }\right), \sigma_{\varphi}^{2}\right)
$$

Sexual activity initiation Not all women start their sexual life at the same time. Clearly, if sexual initiation has not occurred, the contraceptive use and abortion decisions are not relevant and should not be included in the woman's choice set. Therefore, an indicator for sexual initiation (si) is included as a state variable. A single woman of age $a$ who is not sexually active yet will become sexually active with probability $P\left(s i_{a+1}=1 \mid s i_{a}=0\right)=q^{s i}(a$, type $)$. I assume $s i=1$ for all women who are or have been married or cohabiting.

Sexual activity Recall the level of sexual activity $S X$ is an argument in the probability that a woman becomes pregnant (equation (7)). I assume this variable can fall into one of three categories: low, medium or high. $S X$ evolves stochastically, with the probability distribution over the different levels being a function of age, marital status and unobserved type:

$$
P\left(S X_{a} \mid \Omega_{a}\right)=q^{S X}\left(a, d m_{a}, \text { type }\right)
$$

\subsection{Pre-determined heterogeneity}

Initial conditions At the beginning of the modeling period, women differ in terms of their religiosity, the age at which they finish high school, and a series of state variables at the time they finish high school: sexual initiation, the county and state where they live and if they have ever had any children.

Unobserved heterogeneity Besides this heterogeniety, I assume that women have some relevant characteristics that are unobservable in the data. Following the standard approach in the literature (Heckman and Singer (1984), Keane and Wolpin (2001)), and as I have hinted repeatedly while describing the model, I divide women in $L$ different unobserved types, with $L=4$. These types differ in terms of their initial human capital -and hence wage offers-, the expected earnings of their husbands, the probability distribution over marital status and sexual behavior, and their preferences for abortion, leisure and school attendance.

The distribution of women over these types depends on the other initial conditions $X$ :

$$
P(\text { type } \mid X)=q^{\text {type }}\left(\underline{a}, n_{\underline{a}}, \text { loc }_{\underline{a}}, \text { regtype }_{\underline{a}}, \text { si }_{\underline{a}}\right)
$$

\subsection{Timing}

Within each period, the timing of events is the following:

1. Preference and wage shocks are realized. Marital status and sexual activity are realized. Children are born.

2. Women make contraceptive choices.

3. Pregnancies occur.

4. Conditional on the pregnancy status, women make all other choices (if applicable): schooling, labor supply and abortion.

\footnotetext{
${ }^{16}$ The age subscript in $\varphi_{a}$ refers to the fact that it changes if women divorce or separate and start a new relationship. $\varphi$ is fixed within a marital relationship.
} 


\subsection{State space}

Based on all of the above, a woman's state space $(\Omega)$ is composed by:

- Schooling $\left(S_{a}\right)$ and labor market experience $\left(H_{a}\right)$.

- School attendance $\left(s_{a-1}\right)$ and labor supply $\left(h_{a-1}\right)$ in the previous period.

- Marital status $\left(M_{a}\right)$.

- If married or cohabiting: duration $\left(\operatorname{dur}\left(M_{a}\right)\right)$ in the current marital status and permanent earnings component of the husband $\left(\varphi_{a}\right)$.

- Number of children in each age group $\left(n_{a}, N_{a}^{5}, N_{a}^{17}\right)$.

- Sexual activity status (both initiation $s i_{a}$ and level of sexual activity $S X_{a}$ ).

- If the woman has chosen a sterilization before.

- Idiosyncratic disutility for abortions $(\xi)$, local availability of abortion services $l o c_{a}$, and current mandatory counseling regulation in the state in which she lives rega .

- Unobserved type.

\subsection{The problem}

At each age, a woman in the model is assumed to maximize the present value of expected lifetime utility from that age onward. Her value function (i.e. the maximized present value of her expected lifetime utility) is then:

$$
V_{a}\left(\Omega_{a}\right)=\max E\left[\sum_{\tau=a}^{A} \beta^{\tau-a} U_{\tau}(\cdot) \mid \Omega_{a}\right]
$$

The expectation in (10) is taken over current and future pregnancies and miscarriages, the distribution of future preference shocks, and the probability distribution over the transition of state variables (sexual initiation, marital status, sexual activity status). The problem can be re-written in a dynamic programming framework, expressing the value function as the maximum over alternative specific value functions. For this, given the assumptions on $U$, the flow utility can be separated into a part that depends on the birth control choice $(B)$ and another one that depends on the combination of other alternatives $\tilde{U} \cdot{ }^{17}$ Thus, the Bellman equation can be written as:

$$
V_{a}\left(\Omega_{a}\right)=\max _{k \in C H_{a}^{K}\left(\Omega_{a}\right)} \Pi_{k}\left(\Omega_{a}\right) W_{k}^{1}\left(\Omega_{a}\right)+\left(1-\Pi_{k}\left(\Omega_{a}\right)\right) W_{k}^{0}\left(\Omega_{a}\right)+B_{a}^{k}\left(\Omega_{a}\right)
$$

where

$$
W_{k}^{f}=\max _{j \in C H_{a}^{J}\left(\Omega_{a}, f\right)} \tilde{U_{a}^{j}}+\beta E\left[V_{a+1}\left(\Omega_{a+1}\right) \mid d_{a}^{j}=1, d b c_{a}^{k}=1, f, \Omega_{a}\right]
$$

$W_{k}^{f}$ is the value function at the time of pregnancy, given the pregnancy status and the contraceptive choice $k$. The combination of abortion, schooling and labor supply choices $(j)$ is indicated by $d_{a}^{j}=1$. $C H^{J}$ and $C H^{K}$ are the choice sets for the $j$-indexed and $k$-indexed alternatives, respectively. The continuation value at age $A, V_{A+1}$, is assumed to be zero.

\footnotetext{
${ }^{17} B^{k}=-\left(e_{k}+c_{k}^{b c}\right)$ while $\tilde{U}^{j}=g_{j}+C_{j}+c_{k}^{b c}$. The $j$ and $k$ indexes in $e_{k}, g_{j}$ and $C_{j}$ denote that these functions are evaluated when the respective alternative $(j$ and $k$ ) is chosen.
} 


\subsection{Solution of the model}

I solve the model by backwards recursion. At each age and point in the state space, I integrate over all the random outcomes to build the expectation over the continuation values (which I will refer to as Emax). For this, I need to integrate over 3 birth control preference shocks ( $\nu$ 's), 4 other preference shocks $(\eta$ 's) and 2 wage and income shocks ( $\varepsilon$ 's). This is done through a combination of a distributional assumption on the $\nu$ 's and numerical integration over $\eta$ 's and $\varepsilon$ 's. I also need to integrate over the discrete variables in the state space that evolve stochastically $(S X, s i, m c, M)$ for which I use the actual discrete probability distributions.

For the Emax function, I take $D$ draws of the $\eta$ 's and $\varepsilon$ 's from their respective joint distributions. Conditional on each draw $d$ of these shocks, I build $W_{d}^{1}$ and $W_{d}^{0}$ value functions according to equation (12). Then, I calculate the expected value of equation (11) (the expectation is over the distribution of the birth control preference shocks) to build the expected value function for draw $d$. I then average over the $D$ draws to calculate the value of the Emax at age $a$.

Because the state space is too large, solving the model at every state space point is computationally unfeasible. Thus, I approximate the Emax function in the same way as Keane and Wolpin (2001). At each age, I solve the model for a random sample of the state space points, where every feasible combination of state variables is drawn with the same probability. Then, I regress the Emax values on a function of the state variables that includes linear, quadratic, and interaction terms. When moving back to the previous period, I interpolate the Emax function using the coefficients of the regression I previously estimated. I finally integrate over all the possible transitions, as described before, to build the appropriate continuation values to solve the model in the current period's random sample of state space points.

\section{Data}

\subsection{NLSY97}

To estimate the model, I use data from the National Longitudinal Survey of Youth 1997 (NLSY97). The NLSY97 follows a nationally representative sample of young men and women living in the United States and born between 1980 and 1984. From the original sample, 4384 respondents are female. ${ }^{18}$ The first round of interviews took place in 1997 and the respondents have been followed ever since through yearly interviews. To date, the last round of information that has been released is round 15, corresponding to survey year 2011.

The NLSY97 asks questions and gathers detailed information on the labor market, fertility outcomes, sexuality, and socio-demographic characteristics, which I use to build most of the variables that appear in the model. In particular, the following information is available for some or all of the rounds of the survey:

- Detailed weekly employment histories.

- Detailed monthly marriage and cohabitation histories.

- Information on all pregnancies and outcomes, including miscarriages and induced abortions.

- Whether a person has ever had sex or not, and the amount of sexual activity in the last year if she has.

- The contraceptive method used, if any, and the fraction of sexual relations in which a contraceptive method was used.

- Earnings during the previous year.

- Income of the husband/partner during the previous year.

${ }^{18}$ This includes the main sample and the additional over-sampling of hispanic and black respondents. 
- School enrollment and achievement.

- Detailed geographic information (only available in the confidential 'Geocode' version of the data).

The timing period in the model is a year (age of the woman). I assume that each period in the data starts in September given that the modeling period needs to coincide with the academic calendar. All variables are built according to this timing.

Abortions, pregnancies and miscarriages The NLSY97 asks questions about the outcomes of pregnancies and, if pregnancies did not end in a live birth, what was the exact outcome of the pregnancy. It also asks the date of birth for children born to the woman. Using the dates reported for abortions, I first define the period in which these occur and assume the pregnancy happened in the same period. Then, using the birth dates, I define when a child was born and assume the pregnancy occurred in the period immediately before. In the event that both of these end up defining the pregnancies in the same period, given that the model allows for at most one pregnancy per year, I give priority to the abortion date and assume that birth occurred in the period immediately after the one originally defined, adjusting the corresponding pregnancy accordingly. Finally, miscarriages are defined using the same variable as abortions, but are defined last, only recording them when there is no pregnancy ending in birth or abortion during the period.

The questions about pregnancies not ending in live births are asked in a self-administered part of the survey. This is done to reduce misreporting of sensitive issues such as abortion. Nevertheless, it is clear that many abortions are still misreported (either as non-pregnancies or as miscarriages). When I compare abortion rates by age groups calculated from the NLSY97 with those coming from the Centers for Disease Control and Prevention (CDC) in 2005 (Ventura et al., 2009) and the Guttmacher Institute (GI) (Jones and Kavanaugh, 2011), I find that, for women ages $20-24$, only $47 \%$ of the abortions are reported. This fraction goes down to $33 \%$ for women ages $25-29$. These estimates are almost identical to the ones obtained by Jones and Kost (2007) using a different but similar self-reported survey (NSFG). This is, of course, a crucial issue for this paper. Thus, in section $5.1 \mathrm{I}$ will carefully describe how I incorporate these measures of the degree of misreporting, constructed using aggregate abortion rates, into the estimation procedure I use.

Contraception NLSY97 questions include up to 15 different contraceptive method options. I group this into the three categories (including no method at all) described earlier. I classify a woman as using standard contraception if she chooses a "modern" contraceptive method (i.e. excluding options like withdrawal or calendar based methods) and she reported that the fraction of times it was used was at least $80 \%$.

School attendance To build the school attendance variable, I first use the information on schooling achievement and classify a woman as having attended school for a year if she reports a one year increase in the highest grade achieved. This implies that I only consider attendance that leads to completion of a full academic year. In this way, women who attend part of the year are assumed to not attend at all. For women that miss an interview or women who report an inconsistent increase (e.g. 3 year jump in one year), I use attendance reports and achievement at later ages, if available, to recover the information.

Labor supply The total number of hours worked is calculated directly from employment histories. I define working more than 1500 hours in a given year as full time work, working between 500 and 1500 hours as part-time, and working under 500 hours as no work at all. 
Initial age Women in the estimation sample leave high school when they are between 17 and 20 years of age. I assume that the initial age can take only one of two values, 18 or 19, and will treat women who left high school at 17 as if they were 18. Similarly, women who were 20 are classified as being 19 . I do this to ensure that enough women in my sample fall into each possible combination of values for the initial conditions.

Initial number of children A very small fraction of the sample $(0.91 \%)$ have more than one child at the time of high school graduation. I assume that these women have only one child. Thus, women can have either one or no children at the beginning of the modeling period.

Religiosity The NLSY97 asks three questions that capture how religious the respondent is in some, but not all, of the rounds. ${ }^{19} \mathrm{I}$ use this information to classify women in three different groups which I denote as "Low", "Medium" and "High". I make the simplifying assumption that religiosity doesn't change over time, and thus I use the information for 2005 to categorize the respondents. ${ }^{20}$

\subsection{Guttmacher Institute Census of Abortion Providers and policy reports}

Provider availability The Guttmacher Institute (GI) collects different kinds of information regarding abortion patients and providers on a regular basis. In particular, GI carries on a periodical census of abortion providers and surveys a sample of them and their patients. This allows the GI to collect information on virtually all abortion service providers in the U.S. and some aggregate characteristics of their patients. Using this information I am able to define which counties in the U.S. have an abortion provider and which ones do not. I only consider abortion providers handling more than 400 cases per year. These providers accounted for more than 94\% of abortions in the U.S. in 2008 (Jones and Kooistra, 2011). Most importantly, most of the smaller providers (from which around a third have less than 30 cases per year) are not listed in yellow pages and are not easily accessible to most women. The census of abortion providers was not carried out every year during my sample period. Thus, I only have information on provider availability for the the following years: 2000, 2004, 2005, 2007 and 2008.

Mandatory counseling regulation The GI also publishes reports on state policies regarding abortion every six months. ${ }^{21} \mathrm{I}$ use the information from these reports, supplemented with information on laws directly available from NARAL Pro-choice or the laws themselves, to define which states had implemented mandatory counseling laws in any given year. ${ }^{22}$

Connecting geographical information with NLSY97 data Finally, I use these geographical information and the Geocode version of the NLSY97, which provides the location of each respondent, to define which women live in a state with mandatory counseling regulation and in a county with or without a provider at any given point in time.

\footnotetext{
${ }^{19} 2002,2005,2006$ and 2008.

${ }^{20}$ I use other years' answers if the information is not available in 2005 for a particular woman.

${ }^{21}$ The series of reports, the most recent of which are available in the Guttmacher Institute's website, are called "State Policies in Brief".

${ }^{22}$ NARAL Pro-choice, formerly known only as NARAL, is an advocacy group that opposes regulation of abortion services. Their web page provides extensive information about abortion laws that is publicly available.
} 


\subsection{Out of pocket cost of contraception and abortion}

Because of the linearity in consumption, intercepts in the utility function cannot be separately identified from monetary costs in the budget constraint. Thus, I use average prices for contraceptive methods and abortion to assign values to the monetary costs. ${ }^{23}$

- The monetary out of pocket cost of an abortion $\kappa_{0}$ is set to $\$ 470$, the median price reported in Jones and Kooistra (2011) which comes from the GI census of abortion providers. This price has been fairly stable during the sample period, as presented by (Beauchamp, 2012).

- The cost of standard contraception $(k=1)$ is set at $\$ 360$. In the NLSY97 sample, from the women I categorize as using this method, the majority uses the contraceptive pill, with most of the remainder using condoms only. This is consistent with the patterns presented earlier in Table 2. Therefore, I set the value for this parameter based on the prices of contraceptive pills. Contraceptive pill prices range between $\$ 15$ and $\$ 50$ per month out of pocket (Planned Parenthood). Assuming a cost of $\$ 30$ per month, the annual cost of this methods is $\$ 360$.

- The cost of a sterilization is calculated to be between $\$ 1500$ and $\$ 6000$ (Planned Parenthood), and this cost is paid once. Based on these estimates, I set $c_{2}^{b c}=\$ 4000$.

\subsection{Sample selection}

As I mentioned earlier, I restrict my attention to women who are high school graduates ( $84.3 \%$ of the NLYS97 sample). Therefore, this is the first criterion of selection of the sub-sample that I use to estimate the model. I also drop from the sample women who are high school graduates but graduated after the year in which they turned 20 or before the year in which they turned 17. I do this for two reasons. First, as age at graduation is one of the initial conditions in the model, the small number of women graduating at these ages becomes an issue for the estimation of the distribution of initial characteristics and the identification of the model's parameters and the distribution over unobserved types (i.e. there would not be enough variation conditional on initial characteristics). Furthermore, these women are potentially different from all other in unobserved ways that I cannot control for, even after allowing unobserved heterogeneity to be correlated with the age at graduation and other initial conditions. Table 3 shows the number of observations lost at each stage of the sample selection process.

Table 3: Observations dropped at each stage of sample selection

\begin{tabular}{lcc}
\hline Reason & Dropped & Remaining \\
Not a high school graduate/ No GED & 684 & 3700 \\
Graduated from High School before 17 & 14 & 3686 \\
Graduated from High School after 20 & 163 & 3523 \\
\hline
\end{tabular}

\subsection{Descriptive statistics}

Table 4 describes the data in terms of the initial conditions of the model: age, presence of children, sexual initiation, availability of an abortion provider in the county of residence at the time of graduation, if the state in which they live at this age ever imposes mandatory counseling regulation and religiosity.

\footnotetext{
${ }^{23}$ Setting these costs in this way has clearly no effect on the estimation of the model. They are only relevant as guidelines when performing counterfactuals.
} 
Table 4: Distribution of initial conditions

\begin{tabular}{lc}
\hline Age finished high school & $64 \%$ \\
\hline 18 & $36 \%$ \\
Religiosity & \\
Low & $32 \%$ \\
Medium & $51 \%$ \\
High & $16 \%$ \\
At initial age & \\
Has children & $13 \%$ \\
Has initiated her sexual life & $77 \%$ \\
Lives in a county with abortion provider & $54 \%$ \\
Lives in a state that ever imposes mandatory counseling & $49 \%$ \\
Lives in a state with mandatory counseling & $29 \%$ \\
\hline
\end{tabular}

Table 5: Pregnancy and choice distributions, by age

\begin{tabular}{rcccccccc}
\hline & Pregnant & Abortion & Enrolled & \multicolumn{2}{c}{ Working } & \multicolumn{2}{c}{ Birth control } \\
Age & & & & Part time & Full time & No & Standard & Sterilization \\
\hline 18 & 0.11 & 0.016 & 0.58 & 0.43 & 0.22 & 0.35 & 0.64 & 0.00 \\
19 & 0.11 & 0.019 & 0.49 & 0.42 & 0.28 & 0.42 & 0.58 & 0.00 \\
20 & 0.12 & 0.018 & 0.43 & 0.39 & 0.35 & 0.48 & 0.52 & 0.00 \\
21 & 0.13 & 0.013 & 0.37 & 0.37 & 0.39 & 0.51 & 0.49 & 0.00 \\
22 & 0.13 & 0.017 & 0.25 & 0.29 & 0.49 & 0.54 & 0.46 & 0.00 \\
23 & 0.13 & 0.013 & 0.17 & 0.24 & 0.56 & 0.56 & 0.43 & 0.00 \\
24 & 0.12 & 0.009 & 0.15 & 0.22 & 0.59 & 0.56 & 0.44 & 0.00 \\
25 & 0.12 & 0.007 & 0.13 & 0.20 & 0.59 & 0.56 & 0.43 & 0.00 \\
26 & 0.11 & 0.011 & 0.11 & 0.19 & 0.59 & 0.56 & 0.44 & 0.01 \\
27 & 0.11 & 0.007 & 0.12 & 0.20 & 0.59 & 0.55 & 0.44 & 0.02 \\
28 & 0.10 & 0.007 & 0.11 & 0.18 & 0.58 & 0.55 & 0.42 & 0.03 \\
29 & 0.07 & 0.002 & 0.11 & 0.19 & 0.57 & 0.57 & 0.39 & 0.04 \\
30 & 0.04 & 0.004 & 0.11 & 0.18 & 0.59 & 0.55 & 0.39 & 0.06 \\
\hline
\end{tabular}


Table 5 presents the fraction of women who had a pregnancy and the choice probabilities for the decisions in the model, conditional on age. Some patterns are worth noting. First, although most of the school enrollment occurs in the late teens and early twenties, a significant fraction of women continue to be enrolled up to age 30. As age increases, women also tend to switch from part time to full time jobs. Part of this is due to many women taking part time jobs while they study. The age profile of contraceptive use follows a similar pattern as the one presented earlier in Table 2. With age, women tend to substitute standard contraceptive methods for permanent sterilization. Consistent with the information presented in Table 1, abortions (and pregnancies) are most prevalent in the early twenties.

Finally, Table 6 presents the distribution of some state variables conditional on age. By age 30 the average woman has accumulated 14.6 years of schooling and $40 \%$ of women have at least four years of college. Average labor market experience is 15 thousand hours of work (Column 4). The next four columns show the fraction of women living in each of the four kinds of locations, defined according to the state-specific regulation and the availability of an abortion provider in county. The changes in the distribution of location types as women in the sample get older reflect the changes over time in mandatory counseling restrictions imposed by states and provider availability at the county level. The number of states with mandatory counseling laws increased from 12 to 25 between 1997 and 2011 (sample period). Of the 258 counties with a provider in 2000 (the first year for which I have these data), 19 (7\%) did not have one in 2008. 23 counties without a provider in 2000 had one in $2008 .{ }^{24}$ With respect to marital status, cohabitation is more frequent than marriage at younger ages. However, marriage becomes increasingly frequent as age increases and becomes more common than cohabitation by age 24 . Finally, the mid-twenties are the ages at which more women have children. The number of children ages 1 to 5 and 6 to 17 increase accordingly.

\section{Estimation}

I estimate the model by Simulated Maximum Likelihood (SML). To build the likelihood function, I follow the approach introduced by Keane and Wolpin (2001) and formalized in Keane and Sauer (2010), in which unconditional probabilities are used to construct the likelihood. The reasons for following this approach are twofold. First, because the dimension of the shock vector is too large, and because of the way in which the shocks enter the utility function, it is virtually impossible to define the thresholds required for the choice probabilities and thus to use a smooth unbiased simulator as, for example, GHK. Also, because some women leave the sample during some periods, there are some state variables (the ones that are not collected through event histories) that are not observed in some periods. To use conditional simulations, I would need to drop these women from my sample or integrate over all possible transitions of state variables when these are not observed.

Unconditional simulations of each woman's contribution to the likelihood require the plausible assumption of measurement error in all outcome variables, as well as the specification of a stochastic process for each one of these variables. This is particularly useful in this paper because it provides a natural way to address the crucial issue of abortion underreporting, as I will present in detail in the next section. I will not describe this SML methodology in full detail here (a complete description can be found in Keane and Wolpin (2001) and Keane and Sauer (2010)). The basic idea is to simulate full histories (sequences of choices and outcomes) for each woman at each iteration, based on the current value of the parameter vector. The contribution to the

\footnotetext{
${ }^{24}$ For the purpose of showing the age distribution of local conditions in Table 5, I have assumed that provider conditions remain constant and equal to the last year available when the information is missing.
} 


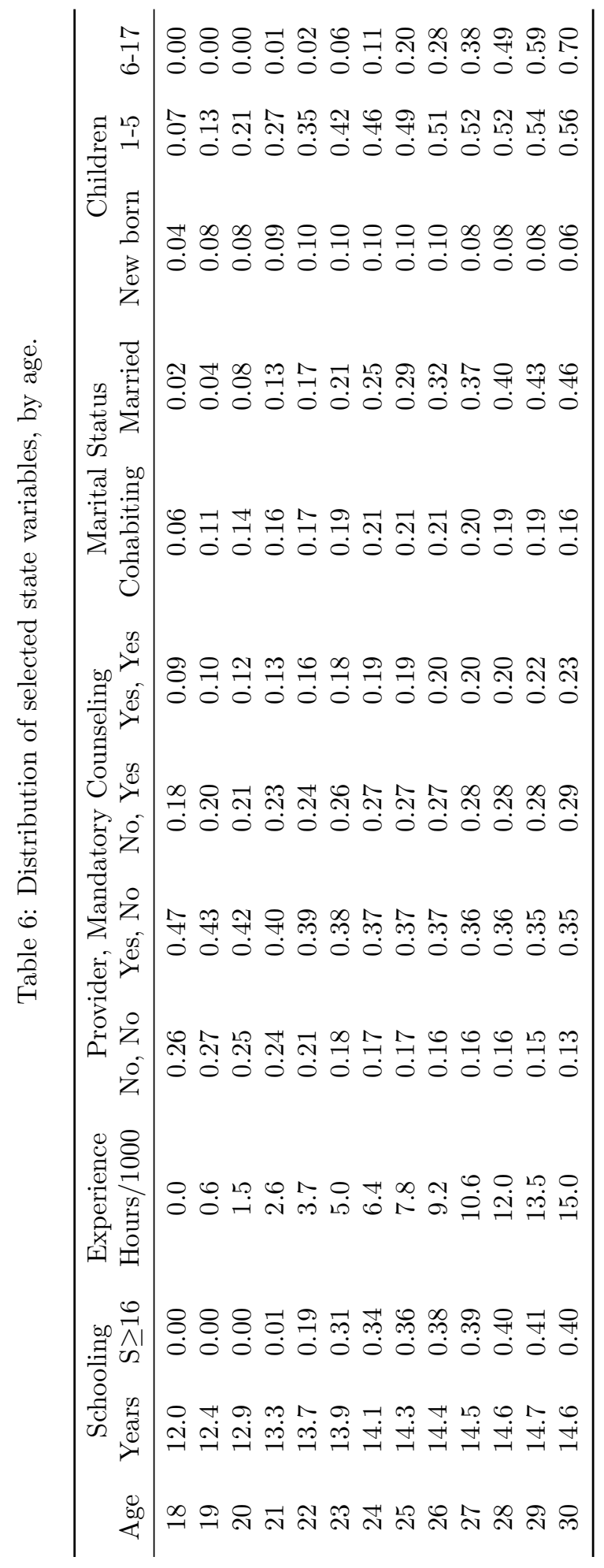


likelihood is built based on a frequency simulator of the full sequence of decisions, rather than the choices at a point in time conditional on the state space. Because of the large amount of choices and periods, as well as the fact that some outcome variables are continuous (e.g. wages), the probability of a simulated history and an observed one coinciding is zero. The measurement error assumption directly provides non-degenerate probability assessments of the likelihood of a simulated story being the same as the observed one. The simulated likelihood for each individual is then calculated as the mean over all of these likelihood objects relating a particular simulated history to the data.

As it is standard, I assume that the measurement error in all outcomes, except for abortions and all other fertility outcomes, is unbiased. The specifics on these unbiased error processes can be found in Appendix B.

\subsection{Biased misreporting of abortions}

As described in Section 4, the degree of misreporting of abortions is substantial in the NLSY97 data. Also, as introduced in the previous section, the SML procedure I use for estimation requires the assumption that all outcomes are measured with error in the data. Thus, this characteristic of the estimation procedure fits quite nicely with the misreporting problem and provides a natural way to address it.

Pregnancies, abortions, miscarriages, and births are not independent events. Thus, a single measurement error process needs to be specified for these events jointly. I assume that these fertility related outcomes in the model are misreported with bias. Although previous research using the same estimation procedure has assumed that the measurement error process for the observed outcomes is unbiased (e.g. Keane and Wolpin $(2001,2010)$ ), this is by no means necessary, as put forward in Keane and Sauer (2010). Thus, in this section I define the characteristics of the biased measurement error process for the fertility variables and propose how to include measures of aggregate abortion rates to aid in the identification of the parameters of this process (and therefore the parameters of the model). In what follows, I drop the age subscript to make notation easier.

There are four possible fertility outcomes, which stem from the feasible combinations of $f, a b, m c$ and $n$ : no pregnancy, abortion, miscarriage and a birth. I specify the measurement error process in terms of indicators for each of these outcomes: $n p, a b, m c$, and $b$, respectively. Throughout this section, $\tilde{x}$ will denote a reported variable, given the measurement error process, while $x$ will denote the true one, given the model. Let $\pi_{j, k} \equiv \operatorname{Prob}(\tilde{k}=1 \mid j=1)$. For example, $\pi_{a b, n p}=\operatorname{Prob}(\tilde{n p}=1 \mid a b=1)$, the probability of no pregnancy being reported given an abortion occurred. These $\pi_{j, k}$ 's are the measurement error parameters, which are contained in the $4 \times 4$ matrix $\Pi^{f e r}$. Denote also $P_{j} \equiv \operatorname{Prob}(j=1)$ and $\tilde{P}_{j} \equiv \operatorname{Prob}(\tilde{j}=1)$. For instance, $P_{a b}$ is the frequency of abortions predicted by the model, while $\tilde{P}_{a b}$ is the frequency of reported abortions, given the predictions of the model and the measurement error process.

If the measurement error process were unbiased, then $P_{j}=\tilde{P}_{j}$ for all of these outcomes. Imposing this restriction would make all of the probabilities functions of only one parameter and the observed frequencies of the outcomes. ${ }^{25}$ However, in this biased case where there is no imposed relationship between $P_{j}$ and $\tilde{P}_{j}$, the $\pi_{j, k}$ 's are, in principle, allowed to move "freely". This doesn't prevent the identification conditions presented in Haussman et al. (1998) from being satisfied. However, given the strong bias in the abortion reports, one would want to add information that would help with the identification of these measurement error rates (and thus the model's parameters). This can be done by including "true" aggregate abortion rates from external sources in the estimation. The way in which I include these rates follows the same idea as the unbiased measurement error process: I impose a restriction on the relationship between $P_{a b}$ and $\tilde{P}_{a b}$.

\footnotetext{
${ }^{25}$ See Appendix B for the details on this standard unbiased case.
} 
Given the measurement error process, we have:

$$
\tilde{P}_{a b}=\pi_{a b, a b} P_{a b}+\pi_{n p, a b} P_{n p}+\pi_{m c, a b} P_{m c}+\pi_{b, a b} P_{b}
$$

Divide by $P_{a b}$ on both sides to get:

$$
\frac{\tilde{P}_{a b}}{P_{a b}}=\pi_{a b, a b}+\frac{\pi_{n p, a b} P_{n p}+\pi_{m c, a b} P_{m c}+\pi_{b, a b} P_{b}}{P_{a b}}
$$

Now, let $\rho$ be the ratio of the observed frequencies of abortion in the NLSY97 to aggregate abortion rates from the CDC and the GI. These aggregate rates are obtained directly from abortion provider reports instead of survey data. The restriction I impose is simply that:

$$
\frac{\tilde{P}_{a b}}{P_{a b}}=\rho
$$

Thus, from equation (13) above we get:

$$
\rho=\pi_{a b, a b}+\frac{\pi_{n p, a b} P_{n p}+\pi_{m c, a b} P_{m c}+\pi_{b, a b} P_{b}}{P_{a b}}
$$

Rearranging this we have:

$$
\pi_{a b, a b}=\rho-\frac{\pi_{n p, a b} P_{n p}+\pi_{m c, a b} P_{m c}+\pi_{b, a b} P_{b}}{P_{a b}}
$$

making one of the parameters in $\Pi^{f e r}$ a function of other parameters and $\rho$.

Because of the joint nature of the fertility outcomes, outcomes other than abortions are misreported with bias. This is captured by the fact that the measurement error process is defined for all the outcomes jointly. However, for the purpose of the main question in this paper, it is unnecessary to assume that there exists bias in the report of pregnancies or miscarriages aside from the one that comes from the misreporting of abortions. In other words, in the absence of the underreporting of abortions, the observed pregnancy, miscarriage and birth frequencies would be unbiased estimators of the true pregnancy, miscarriage and birth probabilities. Thus, I nest the biased measurement error process in an unbiased one, similar to the one defined for all outcomes other than the fertility ones. This allows me to write:

$$
\begin{aligned}
& \pi_{j, j}=E^{f e r}+\left(1-E^{f e r}\right) P_{j} \\
& \pi_{j, k}=\left(1-E^{f e r}\right) P_{k} \quad \text { for } j \neq a b
\end{aligned}
$$

Where $E^{f e r}$ is a parameter controlling the degree of unbiased misclassification error that needs to be estimated. This only leaves the probabilities $\pi_{a b, k}$ 's, which determine the fraction of abortions reported as some other outcome $k$, to be specified. In the absence of bias, these would be given by equation (16). However, the bias "adds" a share $1-\rho$ that gets reported as the remaining three outcomes. I first assume that no abortion gets reported as an actual birth aside from those that would occur if the process were unbiased:

$$
\pi_{a b, b}=\left(1-E^{f e r}\right) P_{b}
$$

A fraction $\lambda$ of the biased reports will get reported as miscarriages, while the remaining $1-\lambda$ will be reported as if there had been no pregnancy. I assume $\lambda=1-q^{m c}$. This means that when deciding how to 
report an abortion (that won't get reported as one), women report them as miscarriages at the same rate that miscarriages actually occur. Explicitly:

$$
\begin{aligned}
\pi_{a b, m c} & =\left(1-E^{f e r}\right) P_{m c}+\left(1-q^{m c}\right)(1-\rho) \\
\pi_{a b, n p} & =\left(1-E^{f e r}\right) P_{n p}+q^{m c}(1-\rho)
\end{aligned}
$$

I assume that the level of underreporting of abortions $(\rho)$ varies with age. As I mentioned in section 4 , the fraction of reported abortions for women $20-24$ is $47 \%$ and this number goes down to $33 \%$ for women $25-29$ years old. These fractions are precisely the $\rho$ 's in equation (15). ${ }^{26}$

\section{Results}

The objects of interest for the analysis in this paper are the choice patterns and behaviors predicted by the model as a whole, rather than the estimated values for the parameters themselves. These behavioral predictions are obtained by simulating the model at the estimated parameters. Therefore, I do not include the full set of parameter estimates here and refer the reader to Appendix $\mathrm{C}$ for these and their corresponding standard errors. Before turning to the counterfactual policy simulation that constitutes the key component of the analysis, I first (1) present the predictions of the model with respect to the choices and outcomes of interest and assess how they fit the data, (2) characterize the choice patterns of the unobserved types, given the parameter estimates, as this heterogeneity is crucial for the analysis of the effects of the simulated policies, (3) briefly describe the abortion costs implied by the parameter estimates, and (4) present the distribution of the willingness to pay for an abortion across the population, as it is useful for explaining several of the results of the policy simulation.

When analyzing the effects of policies and characterizing the behaviors predicted by the model, I will focus most of my attention on choice patterns for women ages 18 to 30, together with life-time outcomes (e.g. fertility, earnings, welfare). ${ }^{27}$

\subsection{Model fit}

Figures 2 - 4 graph the observed choice probabilities for the four choices in the model and the pregnancy outcome (abortions and pregnancies are presented as rates per 1000 women). The relevant comparison, in terms of fit, for the abortion and pregnancy rates are the implied "observed" rates, given the biased measurement error process (labeled as "Model-reported"). However, Figure 2 includes the predicted rates as well for reference purposes. The implied reported abortion rate fits the data pretty well. The actual abortion rate, which by construction is larger than reported rate, is consistent with aggregate abortion rates, although it slightly over predicts abortions in the late twenties. The model also predicts the pregnancy rate accurately. ${ }^{28}$ With respect to contraceptive choices, the model predicts the age patterns fairly well. However,

\footnotetext{
${ }^{26}$ To avoid discontinuities caused by the jump between these two different $\rho$ 's, I implement a smoothing procedure. Details can be found in the Appendix.

${ }^{27}$ I will refer to women ages $18-30$ as young women.

${ }^{28}$ The observed drop in the pregnancy rate at ages 29 and 30 in the data is specific to this data set and is mainly due to two particular facts: (i)the number of women observed at later ages is dramatically lower as only the older women within the cohort are observed at that age (making any estimate very imprecise) and (ii) the NLSY97 asks about ALL previous pregnancies in each interview, so the probability that a pregnancy gets reported increases with the distance between the pregnancy date and the date of the most recent interview. Due to the small number of women at this age in the sample, this has virtually no effect
} 
the model predicts a slower increase in sterilization use. Schooling and labor supply choices are predicted very well by the model.

Ideally, one would want to validate the model by comparing its predictions to statistics that do not come from the estimation sample. However, this is not possible in the context of this paper. Holding out a non-random part of the sample as in Keane and Wolpin (2007), for instance, would reduce the number of abortions in the estimation sample. Given that I already need to deal with underreporting of abortions, this is not a feasible option. A second-best option would be to compare the predictions of the model in terms of the effects of policies that I observe in the data to estimates from other studies. Although this would still be an evaluation within sample (I use that information in the estimation), matching those estimates would provide some validation to the model. Unfortunately, all of the reliable estimates from the literature are for (i) a cross-section of women rather than a specific cohort and (ii) a specific state rather than the U.S. as a whole. Nevertheless, in the discussion of the results of the conuterfactual policy analysis I relate my results to what has been found in the literature, showing that both are consistent with each other.

Figure 2: Abortion and Pregnancy rates (per 1000 women)
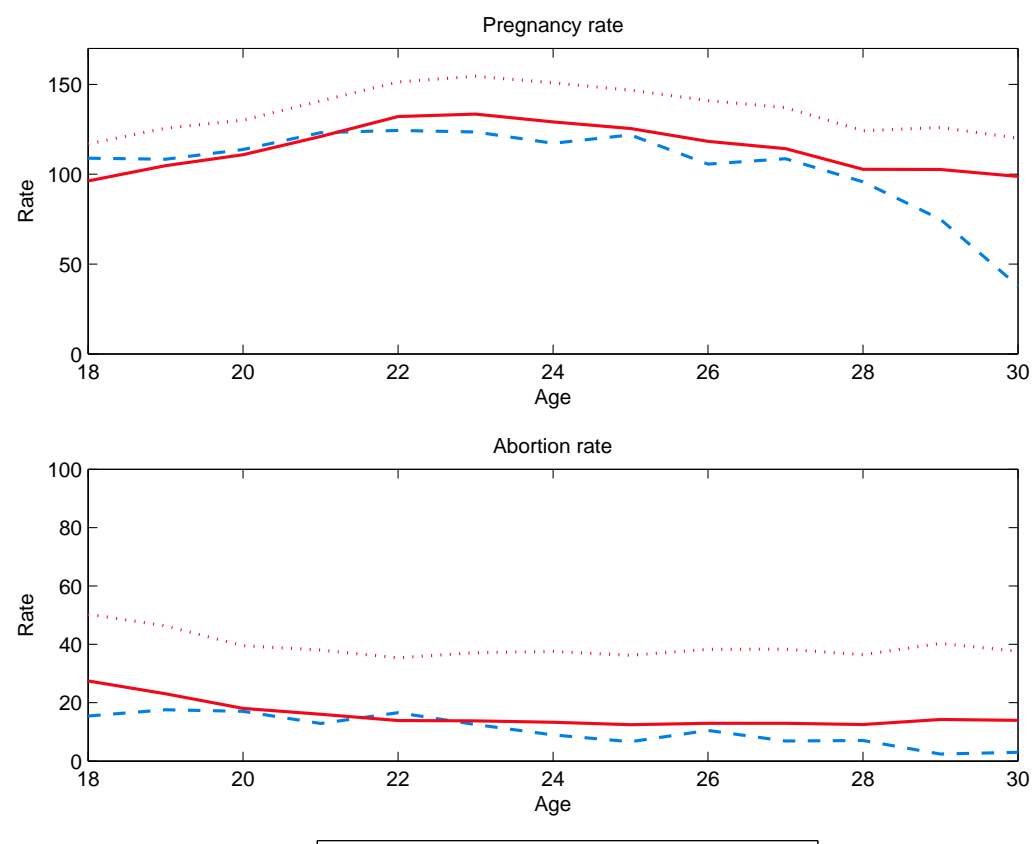

- - - Data $\ldots . \cdots$, Model $\longrightarrow$ Model-reported

on the estimates. 
Figure 3: Contraceptive choices probabilities
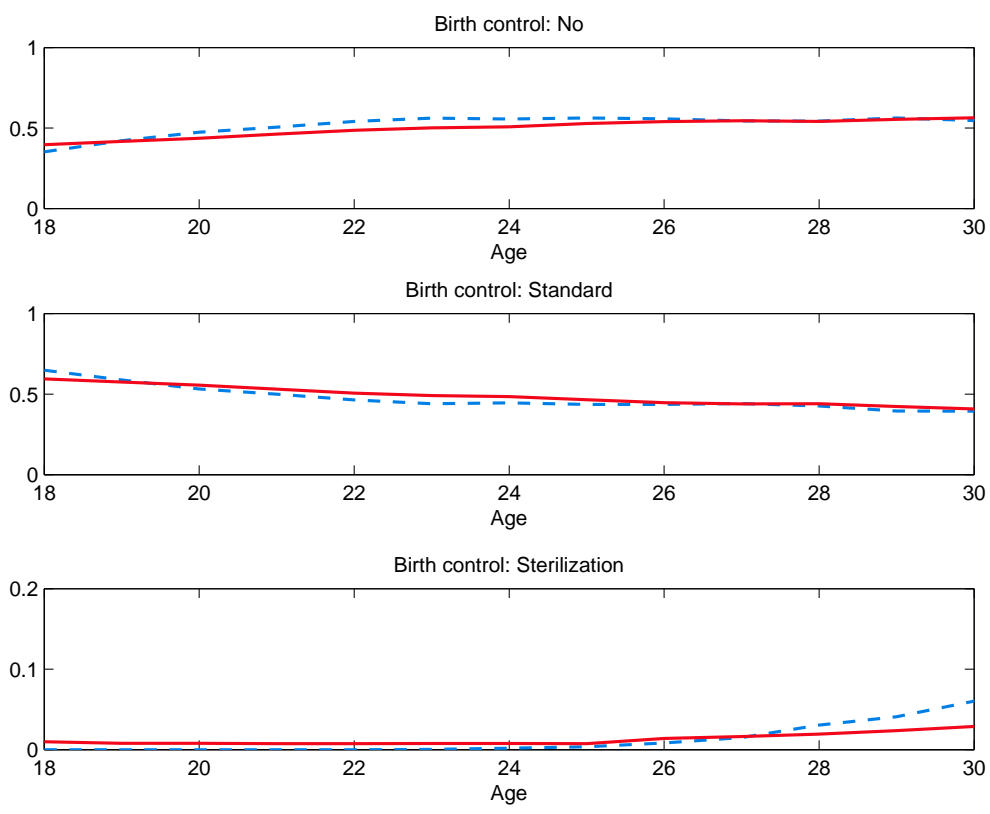

--- Data $\longrightarrow$ Model

Figure 4: School attendance and labor supply probabilities
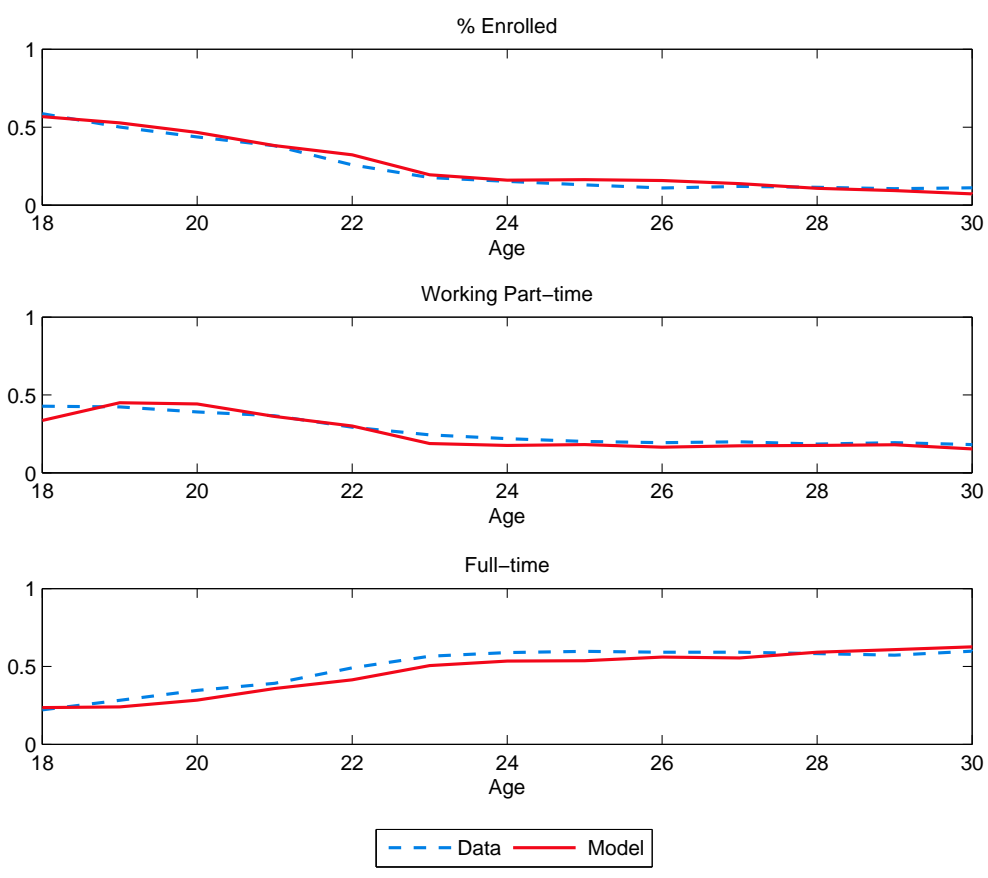


\subsection{Characterization of unobserved types}

Table 7 characterizes the four unobserved types according to their choice patterns, marital status profiles, college graduation rates, and life-time fertility. It also presents the initial human capital (i.e., the intercept in their wage offer function) and the mean psychic $\operatorname{cost} \xi$ for each type, which already takes into account the differences in religiosity across types. It is worth noting, however, that the differences in choices across types depend on several more elements in the model, as described in section 3. Yet, this characterization summarizes the key differences between them.

The types in Table 7 are ordered from the highest to the lowest in terms of initial human capital. Types 1 and 2 can be thought of as the high ability types (high wage offers, everything else constant), whereas Types 3 and 4 are the lower ability types. However, the initial human capital of Type 3 women is still significantly higher than the one of those of Type 4 . The share of women who graduate from college is nearly $75 \%$ for the first two types, while virtually none of the women of Type 3 or 4 finish college. Thus, I will refer to these two groups of types as the college and non-college types, respectively.

Regarding labor supply, the most noticeable difference is between Type 4 women and all the other types. Very few women of this type work and, when they do, they mostly work part-time jobs. Type 3 women the other non-college type - display a a contrasting labor supply behavior. More than two thirds of them work at any age and most of them work full-time jobs. The majority of women of both of the college types works although women of Type 2 choose to work full-time more frequently than women of Type 1 . For both of these types, there is a large switch from part-time to full-time jobs between the "college years" - ages 18-24 - and the late twenties.

Finally, with respect to reproductive choices, Type 1 women have a relatively low abortion rate and a slightly higher rate of contraceptive use when compared to the other college type. This is consistent with the difference in mean psychic costs for women both of these types, as the average cost for Type 1 women is almost three times as large as the one of Type 2 women. Even though the average psychic cost for Type 4 women is one fourth of the cost of Type 1 women, their abortion rate is the lowest of all types at younger ages and very similar to the rate of Type 1 women in the late twenties. Type 2 women have the highest abortion rate of all types at ages 18-24, while Type 3 women are the group with the highest rate at ages 25-30. Contraceptive use is frequent and similar for both of the college types and higher for these women than for those of the non-college types. However, nearly $40 \%$ of women of Type 3 use contraception, which contrasts with the usage among Type 4 women (less than 10\%). As a result of all these choices, the total fertility rates - number of children born over the lifetime- are 1, 0.7, 1.6 and 3.3 children per woman for Types 1 through 4, respectively.

Thus, in order to summarize these patterns in an easier way throughout the discussion, I will refer to Type 1 women as the college and low abortion rate type; Type 2 women as the college and high abortion rate type; Type 3 as the non college-working (and high abortion rate) type; and Type 4 women as the "stay-home" type.

\subsection{Abortion and contraception costs}

In the model, if a pregnancy occurs, the choice of whether to get an abortion or not is determined by the relative benefit of preventing a birth at that point in time and the costs incurred when obtaining an abortion. The relative value of preventing a birth is a function of the woman's particular characteristics, captured by the state variables in $\Omega$ (see equations (11) and (12)). The costs are composed of the out of pocket cost 
Table 7: Characterization of unobserved types

\begin{tabular}{|c|c|c|c|c|}
\hline & \multicolumn{4}{|c|}{ Type } \\
\hline & 1 & 2 & 3 & 4 \\
\hline Share & $36 \%$ & $20 \%$ & $25 \%$ & $19 \%$ \\
\hline \multicolumn{5}{|l|}{ Enrollment } \\
\hline$\overline{\text { ages } 18-24}$ & $61 \%$ & $64 \%$ & $2 \%$ & $0 \%$ \\
\hline ages $25-30$ & $19 \%$ & $23 \%$ & $0 \%$ & $0 \%$ \\
\hline \multicolumn{5}{|l|}{ Part-time work } \\
\hline ages $18-24$ & $48 \%$ & $21 \%$ & $12 \%$ & $38 \%$ \\
\hline ages $25-30$ & $24 \%$ & $3 \%$ & $13 \%$ & $23 \%$ \\
\hline \multicolumn{5}{|l|}{ Full-time work } \\
\hline ages $18-24$ & $31 \%$ & $49 \%$ & $66 \%$ & $0 \%$ \\
\hline ages $25-30$ & $69 \%$ & $90 \%$ & $59 \%$ & $2 \%$ \\
\hline \multicolumn{5}{|l|}{ Abortion rate } \\
\hline ages $18-24$ & 25.3 & 71.1 & 65.8 & 1.7 \\
\hline ages $25-30$ & 16.2 & 47.9 & 76.5 & 18.2 \\
\hline \multicolumn{5}{|l|}{ Using any contraception } \\
\hline$\overline{\text { ages } 18-24}$ & $84 \%$ & $74 \%$ & $43 \%$ & $9 \%$ \\
\hline ages $25-30$ & $67 \%$ & $59 \%$ & $34 \%$ & $7 \%$ \\
\hline \multicolumn{5}{|l|}{ Married } \\
\hline at age 25 & $21 \%$ & $17 \%$ & $22 \%$ & $35 \%$ \\
\hline at age 30 & $28 \%$ & $31 \%$ & $31 \%$ & $47 \%$ \\
\hline \multicolumn{5}{|l|}{ Cohabiting } \\
\hline at age 25 & $13 \%$ & $24 \%$ & $43 \%$ & $29 \%$ \\
\hline at age 30 & $13 \%$ & $20 \%$ & $39 \%$ & $25 \%$ \\
\hline College graduate & $73 \%$ & $76 \%$ & $0 \%$ & $0 \%$ \\
\hline Number of children & 1.0 & 0.7 & 1.6 & 3.3 \\
\hline Mean $\xi$ & $\$ 40,054$ & $\$ 14,352$ & $\$ 7,579$ & $\$ 10,723$ \\
\hline $\begin{array}{l}\text { Wage intercept } \\
\text { (difference w.r.t. Type 1) }\end{array}$ & $0 \%$ & $-2 \%$ & $-10 \%$ & $-17 \%$ \\
\hline
\end{tabular}


$\kappa_{0}$; the additional "traveling" cost imposed by the lack of provider in the county of residence $\left(\kappa_{1}\right)$ and mandatory counseling restriction in the state of residence $(\chi)$; and the idiosyncratic psychic cost $(\xi)$, drawn from a distribution in which the mean depends on the unobserved type and the woman's religiosity. The top panel of Table 8 summarizes these costs and the differences according to the unobserved type and religiosity.

As it can be seen, most of the costs come from the psychic component. The average psychic cost $(\xi)$ in the population is $\$ 22,130$, which is outstandingly larger than the (imputed) out of pocket cost of $\$ 470$. The additional costs imposed by the lack of availability of a provider or the requirement of mandatory counseling and waiting periods are of the same order of magnitude as these out of pocket costs; $\$ 334$ and $\$ 326$, respectively. Thus, even in the most restrictive case - for a woman living in a state with mandatory counseling laws and a county without an abortion provider- all of these costs are less than $6 \%$ of the average idiosyncratic psychic cost.

The mean psychic cost for each type is presented holding religiosity fixed at the least religious category. The qualitative differences already presented in Table 7 still hold. Type 1 women -the college and low abortion rate type- have a substantially higher cost than all other types, while the non-college working type have the lowest. There are substantial differences in terms of religiosity, as expected, particularly between the least religious women and both of the other religiosity categories; the average psychic cost for the least religious group of women is $43 \%$ lower than the one for the most religious women.

The bottom panel of Table 8 shows the imputed out of pocket cost for standard contraception and the additional psychic cost of this contraceptive method. ${ }^{29}$ As it can be seen, the psychic costs are of the same order of magnitude as the out of pocket costs. Compared to the total costs of abortion, the costs of contraception are less than $10 \%$, even for the type with the lowest psychic cost of abortion.

\subsection{The willingness to pay for an abortion}

With the estimated model, it is possible to calculate how much a woman would be willing to pay for an abortion (WP), in excess of all monetary and psychic costs, if she were pregnant. Among women ages 18 to 30 , only $32 \%$ would be willing to pay a positive amount. These are the women that would choose an abortion if they became pregnant. However, only a few of them actually do, as the majority do not become pregnant. Table 9 shows the distribution of WP values among those with a positive WP. The mean WP for this group of women is $\$ 5277$. Only $10 \%$ of them are willing to pay less than $\$ 1088$, while $10 \%$ are willing to pay more than $\$ 9934$.

Two key conclusions can be drawn from these values in Table 9. First, there is substantial heterogeneity in terms of women who value the option of obtaining an abortion at all -and thus would choose to do so if they were pregnant- and those who do not. Therefore, any restriction on abortion will have direct effects on a small subset of the population at any point in time. ${ }^{30}$ Second, even among those for whom the option is valuable, there is large variation in how valuable it is. Upon a pregnancy, a majority of women would be willing to pay relatively large sums of money for an abortion. Comparing these values to the additional costs imposed by the lack of a provider or mandatory counseling restrictions, shown in Table 8 , it can be seen that the additional costs imposed by restrictions are quite small in relative terms to most women's willingness to pay, conditional on pregnancy. Therefore, conditional on pregnancy, these type of restrictions will alter the abortion decisions of few women.

\footnotetext{
${ }^{29}$ The psychic costs of sterilization as these are functions of age, marital status and whether the woman has had children before or not, which makes it very complicated to clearly summarize them for this Table.

${ }^{30}$ This statement refers only to "direct" effects, ignoring for the moment that restrictions also have effects by altering lifetime behaviors and expectations (i.e. the fact that the cost will be higher in the future may alter the value of an abortion today).
} 
Table 8: Abortion and contraception costs

\begin{tabular}{lr}
\hline \multicolumn{2}{c}{ Abortion costs } \\
\hline Out of pocket (data) & $\$ 470$ \\
No provider in county $\left(\kappa_{1}\right)$ & $\$ 334$ \\
Mandatory counseling $(\chi)$ & $\$ 326$ \\
& \\
Idiosyncratic cost $(\xi)$ & $\$ 22,130$ \\
Mean (Overall) & \\
Mean by type (religiosity=low) & $\$ 31,762$ \\
Type 1 & $\$ 10,845$ \\
Type 2 & $\$ 6,263$ \\
Type 3 & $\$ 8,563$ \\
Type 4 & \\
Differences by religiosity (w.r.t. religiosity=low) & $40 \%$ \\
Religiosity=medium & $43 \%$ \\
Religiosity=high & $\$ 360$ \\
\hline \multicolumn{2}{c}{ Standard contraception costs } \\
\hline Out of pocket (data) & $\$ 301$ \\
\hline Utility cost $\left(e_{1}\right)$
\end{tabular}

Table 9: Willingness to pay for an abortion (if positive)

\begin{tabular}{lc}
\hline Willingness to Pay $>0$ & $32 \%$ \\
\hline Mean & $\$ 5,277$ \\
Percentile & $\$ 1,088$ \\
10 & $\$ 2,137$ \\
30 & $\$ 3,116$ \\
40 & $\$ 4,002$ \\
50 & $\$ 4,908$ \\
60 & $\$ 5,916$ \\
70 & $\$ 7,082$ \\
80 & $\$ 8,356$ \\
90 & $\$ 9,934$ \\
\hline
\end{tabular}




\subsection{Counterfactual policy simulation}

I now explore the effects of a set of counterfactual policies on abortion, contraceptive use and human capital accumulation decisions. Recall that the analysis, except when noted otherwise, refers to choices for women ages 18 to 30 and lifetime outcomes. Table 10 summarizes the results of these simulations. The results are presented in terms of their difference with respect to the baseline scenario (i.e. the predictions of the model at the estimated parameters). However, because some of these policies affect a specific group of women instead of the whole population, the baseline is not the same in all cases. For instance, when simulating the expansion of mandatory counseling restrictions to states which do not currently impose this kind of laws, the comparison presented in Table 10 refers to women in those states only. Finally, it is worth noting that all of the effects estimated here are long-run effects as they all assume that (1) all contraceptive decisions are made after learning about the new policy; (2) women have incorporated the new policy into their expectations and assume it will remain in place forever ; and (3) the policy is implemented by the time women leave high school. ${ }^{31}$

\subsubsection{Perfectly enforced ban on abortions}

I begin the policy analysis by considering the extreme case of a perfectly enforced ban on abortions. Several states in the U.S. currently have laws that would automatically ban abortion in the event that Roe v. Wade were overturned, while others have laws that express the intent to limit abortion to the maximum extent allowed by the Supreme Court. Laws and amendments to state constitutions that criminalize abortion in several indirect ways were being discussed or voted on in 2014 in North Dakota, South Dakota and Colorado. ${ }^{32}$ These laws, together with the observed accumulation of restrictions over the last decades, raise the question of what the effects would be if this restrictive impulse were enacted to its fullest extent. Clearly, if abortion were banned at the federal level, it would be extremely unlikely that this could be enforced perfectly. As it is well known, black markets for abortions exist in countries where abortion is illegal. Unfortunately, there is nothing in the data that can be used to infer and extrapolate the size of this potential black market, the price for abortions in that scenario, the cost of risking legal prosecution, or the additional health risks implied by illegal abortion procedures. Thus, the results from simulating a perfectly enforced ban can only be seen as an approximation to this scenario, providing valuable information about the importance of the availability of abortion services for contraceptive choices and human capital accumulation through schooling and labor supply. Moreover, they can be interpreted as the upper bounds on the effect of restrictions on abortion.

Column 1 in Table 10 presents the results of the simulation of the perfectly enforced ban on abortions. As a result of the ban, there is a large increase in the use of contraception among young women. The share of young women using any form of contraception increases by 11.1 percentage points, 10.4 of which correspond to standard contraception, a $23 \%$ increase. This, in turn, reduces the pregnancy rate by 18.6 pregnancies per 1000 women (13\%). A comparison between the change in the number of pregnancies and the total number of abortions predicted in the baseline scenario implies that $47 \%$ of the pregnancies ending in abortion are prevented through increased contraceptive use. The remaining pregnancies are carried to term, increasing the birth rate for young women by 18.6 births per 1000 women ( $21 \%$ increase). Therefore, each abortion is replaced by 0.47 additional births. ${ }^{33}$ Total fertility - the average number of children born to a women in

\footnotetext{
${ }^{31}$ This implicitly assumes as well that the behavior of the NLSY97 cohort can be extrapolated to all future cohorts, given policies and out of pocket costs of abortion and contraception.

${ }^{32}$ These include "personhood" laws that expand the legal definition of "person" or "child" to include unborn fetus and bills that would criminalize the dismemberment of an unborn fetus which occurs in a large fraction of surgical abortion procedures.

${ }^{33}$ The remaining fraction is accounted for by miscarriages.
} 
Table 10: Counterfactual policies. Differences with respect to baseline.

\begin{tabular}{|c|c|c|c|c|c|c|c|c|c|}
\hline \multirow{3}{*}{$\begin{array}{l}\text { Choices and Outcomes } \\
\text { Enrolled }\end{array}$} & \multirow{3}{*}{$\begin{array}{l}\text { Age } \\
18-24\end{array}$} & \multicolumn{8}{|c|}{ Counterfactual } \\
\hline & & \multicolumn{2}{|c|}{ (1) } & \multicolumn{2}{|c|}{$(2)$} & \multicolumn{2}{|c|}{$(3)$} & \multicolumn{2}{|c|}{$(4)$} \\
\hline & & -1.2 & $-3.3 \%$ & 0.0 & $0.0 \%$ & 0.0 & $0.0 \%$ & 0.3 & $1.0 \%$ \\
\hline (ppts.) & $25-30$ & -1.2 & $-10.3 \%$ & 0.0 & $-0.1 \%$ & 0.0 & $0.1 \%$ & 0.1 & $0.6 \%$ \\
\hline & $18-30$ & -1.2 & $-4.9 \%$ & 0.0 & $-0.1 \%$ & 0.0 & $0.1 \%$ & 0.2 & $0.9 \%$ \\
\hline Part-time work & $18-24$ & -1.0 & $-3.3 \%$ & -0.1 & $-0.3 \%$ & -0.1 & $-0.2 \%$ & 0.5 & $1.5 \%$ \\
\hline \multirow[t]{2}{*}{ (ppts.) } & $25-30$ & -0.6 & $-3.4 \%$ & -0.1 & $-0.4 \%$ & -0.1 & $-0.3 \%$ & 0.4 & $2.6 \%$ \\
\hline & $18-30$ & -0.8 & $-3.3 \%$ & -0.1 & $-0.4 \%$ & -0.1 & $-0.2 \%$ & 0.5 & $1.8 \%$ \\
\hline Full-time work & $18-24$ & 0.3 & $0.9 \%$ & 0.0 & $0.0 \%$ & 0.0 & $0.0 \%$ & 0.0 & $-0.1 \%$ \\
\hline \multirow[t]{2}{*}{ (ppts.) } & $25-30$ & -1.4 & $-2.5 \%$ & -0.1 & $-0.1 \%$ & -0.1 & $-0.2 \%$ & 0.8 & $1.5 \%$ \\
\hline & $18-30$ & -0.5 & $-1.1 \%$ & 0.0 & $-0.1 \%$ & -0.1 & $-0.1 \%$ & 0.4 & $0.8 \%$ \\
\hline Contraception: no & $18-24$ & -10.5 & $-24.8 \%$ & -1.4 & $-3.2 \%$ & -1.1 & $-2.8 \%$ & -10.6 & $-25.0 \%$ \\
\hline \multirow{2}{*}{ (ppts.) } & $25-30$ & -11.7 & $-21.5 \%$ & -1.3 & $-2.4 \%$ & -0.7 & $-1.4 \%$ & -15.6 & $-28.8 \%$ \\
\hline & $18-30$ & -11.1 & $-23.0 \%$ & -1.4 & $-2.8 \%$ & -0.9 & $-2.0 \%$ & -13.0 & $-27.0 \%$ \\
\hline \multirow{3}{*}{$\begin{array}{l}\text { Contraception: standard } \\
\text { (ppts.) }\end{array}$} & $18-24$ & 10.6 & $22.1 \%$ & 1.4 & $3.1 \%$ & 1.1 & $2.2 \%$ & 11.1 & $23.2 \%$ \\
\hline & $25-30$ & 10.3 & $23.9 \%$ & 1.3 & $3.0 \%$ & 0.8 & $1.7 \%$ & 17.0 & $39.5 \%$ \\
\hline & $18-30$ & 10.4 & $22.9 \%$ & 1.4 & $3.1 \%$ & 0.9 & $2.0 \%$ & 13.9 & $30.5 \%$ \\
\hline Pregnancy rate & $18-24$ & -18.5 & $-13.2 \%$ & -2.7 & $-1.9 \%$ & -2.1 & $-1.5 \%$ & -18.8 & $-13.4 \%$ \\
\hline \multirow[t]{2}{*}{ (per 1000 women) } & $25-30$ & -18.8 & $-14.1 \%$ & -2.1 & $-1.5 \%$ & -1.1 & $-0.8 \%$ & -24.3 & $-18.3 \%$ \\
\hline & $18-30$ & -18.6 & $-13.6 \%$ & -2.4 & $-1.7 \%$ & -1.6 & $-1.2 \%$ & -21.4 & $-15.7 \%$ \\
\hline Abortion rate & $18-24$ & -40.3 & $-100.0 \%$ & -4.1 & $-8.9 \%$ & -3.1 & $-7.6 \%$ & -13.3 & $-32.9 \%$ \\
\hline \multirow[t]{2}{*}{ (per 1000 women) } & $25-30$ & -38.2 & $-100.0 \%$ & -3.3 & $-7.7 \%$ & -2.1 & $-5.7 \%$ & -16.3 & $-42.7 \%$ \\
\hline & $18-30$ & -39.3 & $-100.0 \%$ & -3.7 & $-8.3 \%$ & -2.6 & $-6.8 \%$ & -14.7 & $-37.4 \%$ \\
\hline Abortions/Pregnancies & $18-24$ & -28.8 & $-100.0 \%$ & -2.3 & $-7.1 \%$ & -1.8 & $-6.0 \%$ & -6.5 & $-22.5 \%$ \\
\hline \multirow[t]{2}{*}{ (ppts.) } & $25-30$ & -28.7 & $-100.0 \%$ & -2.0 & $-6.3 \%$ & -1.4 & $-4.9 \%$ & -8.6 & $-29.9 \%$ \\
\hline & $18-30$ & -28.7 & $-100.0 \%$ & -2.1 & $-6.7 \%$ & -1.6 & $-5.5 \%$ & -7.4 & $-25.8 \%$ \\
\hline Birth rate & $18-24$ & 19.5 & $21.8 \%$ & 1.2 & $1.3 \%$ & 0.9 & $1.0 \%$ & -5.2 & $-5.8 \%$ \\
\hline \multirow[t]{2}{*}{ (per 1000 women) } & $25-30$ & 17.6 & $20.6 \%$ & 1.1 & $1.3 \%$ & 1.0 & $1.1 \%$ & -7.2 & $-8.5 \%$ \\
\hline & $18-30$ & 18.6 & $21.3 \%$ & 1.2 & $1.3 \%$ & 0.9 & $1.1 \%$ & -6.2 & $-7.0 \%$ \\
\hline \multicolumn{10}{|l|}{ Accumulated variables } \\
\hline Schooling & 25 & -0.08 & $-3.3 \%$ & 0.00 & $0.0 \%$ & 0.00 & $0.0 \%$ & 0.02 & $1.0 \%$ \\
\hline (years) & 30 & -0.15 & $-4.9 \%$ & 0.00 & $-0.1 \%$ & 0.00 & $0.1 \%$ & 0.03 & $0.9 \%$ \\
\hline Labor mkt. Experience & 30 & -230 & $-1.5 \%$ & -23 & $-0.1 \%$ & -21 & $-0.1 \%$ & 152 & $1.0 \%$ \\
\hline (hours) & 65 & -642 & $-1.0 \%$ & -21 & $0.0 \%$ & -17 & $0.0 \%$ & 224 & $0.4 \%$ \\
\hline Total earnings & 65 & $-\$ 20,699$ & $-1.9 \%$ & $-\$ 398$ & $0.0 \%$ & $-\$ 358$ & $0.0 \%$ & $\$ 4,823$ & $0.4 \%$ \\
\hline \multirow[t]{2}{*}{ Children } & 30 & 0.24 & $20.3 \%$ & 0.01 & $1.3 \%$ & 0.01 & $1.1 \%$ & -0.08 & $-6.7 \%$ \\
\hline & 44 & 0.42 & $27.8 \%$ & 0.01 & $0.9 \%$ & 0.01 & $0.9 \%$ & -0.19 & $-12.2 \%$ \\
\hline \multirow[t]{2}{*}{$\%$ Children to single mothers } & 30 & 5.44 & $17.8 \%$ & 0.15 & $0.5 \%$ & 0.05 & $0.2 \%$ & 0.11 & $0.4 \%$ \\
\hline & 44 & 4.73 & $18.6 \%$ & 0.09 & $0.4 \%$ & 0.13 & $0.5 \%$ & 1.44 & $5.7 \%$ \\
\hline$\%$ Exactly High School & 30 & 0.43 & $1.0 \%$ & 0.01 & $0.0 \%$ & 0.02 & $0.0 \%$ & -0.21 & $-0.5 \%$ \\
\hline$\%$ Incomplete college & 30 & 1.91 & $11.8 \%$ & 0.07 & $0.4 \%$ & 0.00 & $0.0 \%$ & -0.46 & $-2.9 \%$ \\
\hline$\%$ College grad. or more & 30 & -2.34 & $-5.6 \%$ & -0.08 & $-0.2 \%$ & -0.02 & $0.0 \%$ & 0.68 & $1.6 \%$ \\
\hline
\end{tabular}

\footnotetext{
(1): No abortion.

(2): Mandatory counseling everywhere (results for women in states that do not have Mandatory counseling laws in the baseline).

(3): No provider (results for women living in counties with a provider in the baseline).

(4): Free contraception
} 
her lifetime- increases by $0.42(28 \%)$. Moreover, there is a larger effect on the birth rates for single women, increasing the fraction of children born to single mothers by 5.4 percentage points, for women under 30, and 4.73 percentage points overall.

Apart from the quantitative estimates of these effects, two important and complementary conclusions can be drawn from these results. First, the large degree of substitution between abortion and contraceptive use, consistent with the limited empirical evidence available (Levine et al., 1996; Levine, 2003), suggests ample room for policies that would prevent pregnancies that lead to abortions in the first place, for example by altering the incentives for the use of contraception. The full subsidy on contraception that I simulate at the end of this section falls into this category. Second, even with this large drop in the risk of pregnancy, almost half of the women who would have had an abortion if the option were available would now see their fertility plans altered. This may have effects on other decisions, both directly by altering the opportunity cost of other activities and indirectly through expectations. I now turn to analyze these effects in terms of labor market choices and human capital accumulation.

First, notice that the enrollment rate drops by 1.2 percentage points per year between ages 18 and 30 . This lower enrollment decreases the average accumulated schooling after high school by $4.9 \%$ ( 0.15 years). The share of women with a college degree decreases in a similar way, dropping 2.3 percentage points (5.6\%). The absence of abortion also affects labor supply decisions of young women. For ages 18-24, part-time work decreases while full-time increases slightly. The decrease in part-time work combines a move towards not working, for some women, and a substitution from attending school and working part-time to working fulltime, for other women. Therefore, the accumulated labor market experience by age 30 decreases by roughly $1.5 \%$. However, the effect is smaller when looking at labor market experience accumulated throughout the entire life cycle. On average, women accumulate 640 fewer hours of market experience at age 65 , which is $1 \%$ of the average experience. This means that, even if this policy affects labor supply decisions at a particular point in time (e.g. the fraction of women working at all in their late twenties drops by 1.2 percentage points per year on average), the effects are not significant at all when looked at from a lifetime perspective. Finally, average lifetime earnings fall by $2 \%$ as a consequence of the changes in schooling and labor supply brought by the abortion ban.

These effects on human capital and lifetime earnings refer to all women, even those who would have not had an abortion in the absence of the abortion ban. However, most of the changes in schooling and labor supply decisions come from women who would have had an abortion if the option were available. Thus, Table 11 compares the effects on all women with those on the subset - $42 \%$ of women- who would have had at least one abortion in their lives in the absence of the policy (i.e., those who have at least one abortion in the baseline). Among these women, the share with a college degree decreases by 5.3 percentage points $(14.3 \%)$, while accumulated schooling after high school drops by 0.36 years $(13.2 \%)$. Throughout their lifetime, women who would have had an abortion work 1567 fewer hours (2.4\%), which is equivalent to $\frac{3}{4}$ of a full-time year of work. As a result of these changes in schooling and labor supply, the average loss in lifetime earnings for this subset of women is $\$ 50,784(4.6 \%)$.

Table 11 also presents the average effects in terms of human capital and related measures for the abortion ban, conditioning on the unobserved type. As expected, most of the changes in schooling come from women of the two college types. The share of women who do not graduate from college due to the ban is equivalent 3 percentage points for Type 1, the low abortion rate type, and 6 percentage points for the high abortion rate type. With respect to labor supply, the drop is similar for all types except the college and low abortion rate one, between 700 and 800 hours. This corresponds to only $1 \%$ Types 2 and 3, but $3.4 \%$ for the stay-home 
type (Type 4). With respect to lifetime earnings, the differences are more pronounced, as these combine the effects on schooling and labor supply. The average woman of Type 2, the college-educated and low abortion rate type, earns $\$ 45,744$ less on average $(2.8 \%)$ which contrasts with the $\$ 6,818$ (0.8\%) loss for the no-college working type. For the stay-home type, the small loss of $\$ 8,150$ corresponds to $3.5 \%$ of lifetime earnings.

Although most qualitative differences between types remain when looking at the effects only on women who would have had an abortion (bottom panel), two interesting changes are worth noting. First, the effects on labor market experience for Type 1 women are no longer different from those on the other types. Similarly, the effects on accumulated schooling for this type is roughly the same as for the other college type. This implies that the effects of the abortion ban on schooling and labor supply decisions of women who would not have had an abortion is smaller among Type 1 women than women of the other three types. Second, the effects on the labor supply of the stay-home type (Type 4) become significantly larger than for the other types, both in absolute and relative terms. Women of this type who would have had an abortion work 2277 fewer hours during their lifetime. Because this type is the one that tends to work the least, this decrease is equivalent to $8.5 \%$ of their total hours worked.

Finally, this counterfactual exercise can also be used to calculate the loss in the net present value of lifetime utility (LTU) in the absence of abortion. Table 12 presents summary statistics of the distribution of this loss. Although LTU is measured in dollars, I present the results in terms of the relative loss, as it provides a better assessment of the size of the effects of the abortion ban. The first column presents statistics for all women, whereas column 2 presents them for the subset of women who would have had an abortion had it been available. In the absence of abortion services, the average loss in lifetime utility is $1 \%$ for the whole population and $2 \%$ among those who have had an abortion. More than $50 \%$ of women experience no loss at all. Nevertheless, even among those for whom lifetime utility decreases, the median loss is $1.1 \%$ of their lifetime utility. Thus, the distribution is very skewed to the right. When looking at the entire population, $5 \%$ experience a loss larger than $6 \%$ of their lifetime utility and one out of every hundred women has a loss larger than $15 \%$ of her lifetime utility. These effects are stronger, of course, when restricting to women who ever have an abortion. For $5 \%$ of them, the abortion ban leads to a loss larger than $10 \%$ of their lifetime utility.

\subsubsection{Other restrictions}

Now, I consider the effects of two particular policies that impose more focused restrictions, which are not as extreme as the perfectly enforced ban. First, I take a look at the expansion of mandatory counseling restrictions to the states where these have not been imposed. Note that this is different from asking was the effect of these policies where they have been imposed, as the characteristics of women in those two sets of states are potentially different. Second, I indirectly evaluate the effect of supply side restrictions through its effect on availability of abortion providers at the county level. The results that I present capture the average consequences of all of the providers in a county closing down across women living in counties that with a provider. This policy should not be interpreted as the closing down of all abortion providers - that would take us back to the abortion ban- but rather as the average effect on women who live in a county with a provider if that provider were no longer there.

Extending mandatory counseling restrictions By 2011, the last year in the sample period, half of the states had enacted and implemented mandatory counseling and waiting period restrictions (MC). Column 2 of Table 10 presents the effects of the expansion of these types of policies to the states where they had 
Table 11: Abortion ban: Human Capital and Earnings Losses

\begin{tabular}{|c|c|c|c|c|c|c|c|c|}
\hline \multicolumn{9}{|c|}{ All women } \\
\hline & \multicolumn{2}{|c|}{$\begin{array}{c}\% \text { with college } \\
\text { (ppts.) }\end{array}$} & \multicolumn{2}{|c|}{$\begin{array}{l}\text { Schooling } \\
\text { (years) }\end{array}$} & \multicolumn{2}{|c|}{$\begin{array}{l}\text { Experience } \\
\text { (hours) }\end{array}$} & \multicolumn{2}{|c|}{ Earnings } \\
\hline All & 2.3 & $5.6 \%$ & 0.15 & $4.9 \%$ & 642 & $1.0 \%$ & $\$ 20,716$ & $1.9 \%$ \\
\hline \multicolumn{9}{|c|}{ Type } \\
\hline 1 & 3.0 & $4.2 \%$ & 0.19 & $3.7 \%$ & 379 & $0.5 \%$ & $\$ 22,922$ & $1.7 \%$ \\
\hline 2 & 6.1 & $8.1 \%$ & 0.39 & $6.8 \%$ & 824 & $1.0 \%$ & $\$ 45,744$ & $2.8 \%$ \\
\hline 3 & 0.1 & $12.1 \%$ & 0.02 & $13.0 \%$ & 819 & $1.2 \%$ & $\$ 6,818$ & $0.8 \%$ \\
\hline 4 & 0.0 & - & 0.00 & $0.0 \%$ & 711 & $3.4 \%$ & $\$ 8,150$ & $3.5 \%$ \\
\hline \multicolumn{9}{|c|}{ Women who would have had an abortion (42\%) } \\
\hline & \multicolumn{2}{|c|}{$\begin{array}{c}\% \text { with college } \\
\text { (ppts.) }\end{array}$} & \multicolumn{2}{|c|}{$\begin{array}{l}\text { Schooling } \\
\text { (years) }\end{array}$} & \multicolumn{2}{|c|}{$\begin{array}{l}\text { Experience } \\
\text { (hours) }\end{array}$} & \multicolumn{2}{|c|}{ Earnings } \\
\hline All & 5.3 & $14.3 \%$ & 0.36 & $13.2 \%$ & 1567 & $2.4 \%$ & $\$ 50,784$ & $4.6 \%$ \\
\hline \multicolumn{9}{|c|}{ Type } \\
\hline 1 & 10.4 & $13.8 \%$ & 0.73 & $13.5 \%$ & 1550 & $2.2 \%$ & $\$ 90,363$ & $6.4 \%$ \\
\hline 2 & 11.3 & $14.9 \%$ & 0.73 & $12.9 \%$ & 1560 & $1.9 \%$ & $\$ 87,452$ & $5.4 \%$ \\
\hline 3 & 0.0 & $8.4 \%$ & 0.02 & $15.1 \%$ & 1310 & $1.9 \%$ & $\$ 10,402$ & $1.2 \%$ \\
\hline 4 & 0.0 & - & 0.00 & $0.0 \%$ & 2277 & $8.5 \%$ & $\$ 26,102$ & $8.8 \%$ \\
\hline
\end{tabular}

Table 12: Lifetime Utility Loss

\begin{tabular}{lcc}
\hline & All & Given abortion in BL \\
\hline Mean & $0.9 \%$ & $1.9 \%$ \\
Median & $0.0 \%$ & $1.1 \%$ \\
& & \\
Right tail & & \\
Percentile 90 & $3.6 \%$ & $6.7 \%$ \\
Percentile 95 & $6.1 \%$ & $10.4 \%$ \\
Percentile 99 & $15.5 \%$ & $20.4 \%$ \\
\hline
\end{tabular}


not been imposed at that time. As a result of this additional regulation, both the abortion and pregnancy rates fall. Among women ages 18-30, abortions decrease by 3.7 abortions per 1000 women and pregnancies decrease by 2.4 pregnancies per 1000 women. These changes are equivalent to $8.3 \%$ and $1.7 \%$ reductions, respectively. The lower pregnancy rate is the consequence of a 1.4 percentage points increase in contraceptive use. Only $32 \%$ of the changes in abortion decisions result in new births, making the group of women who might alter their schooling and labor supply choices as a result of these restrictions very small. Thus, it is not surprising that there are no effects of this policy in terms of human capital accumulation.

As mentioned, calculating these effects is not the same as estimating the effect of having imposed mandatory counseling in the states where we observed that it was imposed. Because the states where this occurred are not random, the characteristics of the women living in those states, both observed and unobserved, are not necessarily the same as for the women living in the remaining states. I compare the estimated effects on these two groups of states and find a similar relative change in the abortion rate (8.6\%). However, the effect on the states that do not currently impose these restrictions is $34 \%$ larger in absolute terms (number of abortions per 1000 women), as the abortion rate is higher in these states. The effects on contraceptive use are similar as well. Nevertheless, changes in birth rates between the ages of 18 and 24 would are $54 \%$ larger in the non-mandatory counseling states than in the ones where we these restrictions are observed.

Finally, the effects on abortion rates calculated here are consistent with those obtained by Althaus and Henshaw (1994) and Joyce et al. (1997) when estimating the (short-run) effects of the introduction of a mandatory counseling and waiting period law in Mississippi. They estimate a $10 \%$ decrease in abortion rates Even though their results and mine are not exactly comparable, this similarity provides external validation for the predictions of the model. ${ }^{34}$

Closing of providers Several states have recently enacted laws that impose strict requirements on abortion providers. Because complying with these requirements is very costly for most abortion clinics, these laws are expected to have a substantial effect on the availability of abortion services in the states where they have been enacted. A well known case is a law known as HB2, passed by Texas in 2013, which includes requirements on the facilities providing abortion services and the doctors who can perform abortions. The passing of this law was temporarily blocked by an eleven-hour filibuster carried out by Texas senator Wendy Davis on June 2013, attracting national attention. After the requirement that doctors have admitting privileges in nearby hospitals went into effect, the number of abortion clinics in Texas went down from 41 to 22 (Grossman et al., 2014). The requirement that clinics meet the standards of Ambulatory Surgical Centers (ASC) was blocked by an initial ruling by a Federal Judge, an Appeals Court that reversed it, and a temporary injunction by the Supreme Court. During the few days it went into effect on October 2014, only 7 of the remaining clinics met the ASC standards and the remaining ones shut down. A law containing similar requirements was passed by Louisiana in 2014, while several more are pending rulings on lawsuits that challenged the laws in federal courts in Alabama, Mississippi and Wisconsin.

These laws indirectly affect women who may obtain abortions by affecting the availability of a provider where they live. In the context of the model, a woman's cost of obtaining an abortion increases if there is no abortion provider where she lives. Thus, I simulate the effect of removing the provider for women living in counties where there is a provider. The effects should be interpreted as the average effects on women living in these counties if the abortion providers where they live closes down -for any reason- rather than the effects of closing down a large number or all of the providers.

\footnotetext{
${ }^{34}$ There are several reasons why their results are not exactly comparable to mine: they work with a different time period, their data is from Mississippi residents only, I use data from one cohort alone, and their effects are short-run effects.
} 
The results are similar to the ones obtained when expanding mandatory counseling restrictions. For the average woman between the ages of 18 and 30, the probability of obtaining an abortion decreases by $6.8 \%$ (her own "abortion rate" decreases by 2.6 abortions). ${ }^{35}$ This is partly the result of a 1 percentage point increase in the use of contraception that leads to a lower number of pregnancies. Of the abortions that do not occur as a consequence of the providers closing down, $34 \%$ of result in new births.

For most women who have abortions in these counties, the closing of the provider simply increases the costs they face. Around $93 \%$ of women who live in a county with a provider and have an abortion would still travel to another county to obtain an abortion. Of the few abortions that do not occur, $34 \%$ of result in new births. Thus, the lack of provider changes the abortion choice for very few of the women that have an abortion in the baseline and still become pregnant. A similar conclusion can be drawn for the expansion of mandatory counseling regulations; for most of the women who have an abortion, these policies only make this choice more costly.

\subsubsection{Free contraception}

The previous policies all impose restrictions on abortions, either directly on women or indirectly by affecting the availability of providers. As I have showed, they all have important effects in terms of contraceptive decisions. I now explore a policy that would directly affect the costs of contraception. Particularly, in the estimation of the model, I assumed that the monthly cost of contraception is $\$ 30$ (see Section 4). Column 4 of Table 10 shows the changes that a full subsidy on that amount would induce in terms of the choices in the model.

Contraceptive choices are very responsive to this change in costs. The fraction of women using contraception increases by 12.3 percentage points ( $0.8 \%$ of women switch from sterilization to standard contraception), with the effect being slightly larger for women in their late twenties than for women under the age of 24 . As a result, the pregnancy rate decreases by 19.3 pregnancies per 1000 women. The abortion rate for women ages 18 to 30 falls by 12.4 abortions per 1000 women, a $38 \%$ reduction. The drop in abortions is roughly two thirds of the decrease in pregnancies, implying that a large fraction of the "marginal" women in terms of the contraceptive use decision are also women with a relatively low cost of obtaining an abortion, rather than women who are close to indifference between having a child or not. Given this large drop in abortions, the fraction of pregnancies ending in abortion decreases by 7 percentage points as well. Nevertheless, there is still a drop in the birth rate of around 8\% (6.3 births per 1000 women) on average for young women. This leads to a decline in the total fertility rate of 0.2 children per woman. Interestingly, the fraction of children born to single women increases, particularly after age 30 (almost 2 percentage points). This implies that the rise in contraceptive use is larger for cohabiting and married women than for single women at older ages.

Table 13 shows the effects of the subsidy on contraception costs on the reproductive choices of young women and on lifetime outcomes, by unobserved type. The top panel presents the changes in abortion rates, contraceptive use and children born to a woman by age 30. Notice that, even if there are important changes in abortion and contraceptive choices between ages 18-30 for the two "college types", there are virtually no changes in the number of children born to women of these types by age 30 . Thus, for these types, the main effect of the policy is to induce more contraceptive use among women who would have abortion if they became pregnant. On the other hand, there are large effects on the fertility by age 30 for the "non-college" types. In particular, the average children born to women of the "non-college, working type" - Type 3 - is

\footnotetext{
${ }^{35}$ Grossman et al. (2014) find that the abortion rate for women ages $15-44$ in Texas decreased by $13 \%$ when comparing the rates the year before and after the implementation of the firs set of restrictions in HB2.
} 
0.2 lower. Lifetime fertility for this type decreases by 0.26 children (bottom panel). Thus, most of the effects on reproductive choices for them occur before age 30 .

Interestingly, the timing of the changes in fertility for the "non-college, working" type coincides with changes in labor supply. By age 30, this type of women have accumulated 3.3\% more hours of work. However, these gains are only $0.5 \%$ by age 65 . Thus, the positive effects on labor supply for this type are concentrated on younger ages. In fact, they work slightly less after age 30, showing some substitution from labor supply at older ages for labor supply at younger ages. For the "stay-home" type, there is a small increase in labor supply throughout the life-cycle, which is nevertheless important in relative terms (roughly $2 \%$ ). With respect to schooling, the share of college graduates increases by 1.3 and 1 percentage points for Types 1 and 2 , the "college types", respectively.

Finally, let me briefly relate these results to what the literature has found on the effects of similar policies. A recent study known as the $C H O I C E$ project, which provided free contraception to a large sample of women in the St. Louis area and has been regularly surveying the participants afterwards, collecting information on their contraceptive use, pregnancies and pregnancy outcomes (i.e. births, miscarriages, abortions). However, the sample is composed by women who volunteered for the project and thus it is not random. Moreover, given the research design, there is no appropriate control group for the participants. The CHOICE project focuses on long term contraception reversible methods such as Intra Uterine Devices and also provides information on how to properly use contraception methods. Secura et al. (2014) report the pregnancy and abortion rate for teenagers who participated in the study and compare it to the rates for teenagers in all of the U.S., as well as to the rates for sexually active teenagers in the U.S. They find that, when compared to these two groups, the pregnancy rate for the participants in the project is $40 \%$ and $78 \%$ lower, respectively. The abortion rate is $34 \%$ and $76 \%$ lower. Despite the fact that these results refer to a different population (women between 15 and 19 years old), the focus of the project on long-term contraception and the already mentioned issues with the research strategy, the large differences that they find are consistent with the results that I predict in a qualitative sense. Kearney and Levine (2009) study the effect of federal waivers that expanded the eligibility requirements for Medicaid family planning services, which include access to contraceptive methods. They find that as a result of this policy, the fraction of eligible women who report not using contraception during last sexual intercourse decreased by 5.3 percentage points. Using the implied take-up rates for these services reported in their paper, this suggests that the effect on those who actually received the services lies between 13 and 23 percentage points. These results are consistent with the large increase in contraceptive use that I find in this paper. However, as opposed to Kearney and Levine (2009), I am able to evaluate and quantify the effects of these policies on abortion decisions.

\section{Conclusion}

In this paper, I structurally estimated a dynamic life-cycle model of abortion, contraceptive use, schooling and labor supply decisions of young women in the U.S. To account for the underreporting of abortions in survey data, I specified a biased measurement error process for all fertility outcomes and used aggregate abortion rates as a source of identification for the parameters in that measurement process. I then used the estimated model to analyze policies that increase restrictions on abortions in terms of their effects on reproductive, schooling and labor market choices. I also considered alternative policies that would lower the cost of contraception and affect abortions through the direct prevention of pregnancies.

The results of the simulation of these counterfactual policies show a large amount of substitution between 
Table 13: Free contraception, effects by unobserved type.

\begin{tabular}{|c|c|c|c|c|}
\hline \multicolumn{5}{|c|}{ Reproductive choices of young women } \\
\hline & Type 1 & Type 2 & Type 3 & Type 4 \\
\hline Contraceptive use (ppts.) & $\begin{array}{c}5.6 \\
7.5 \%\end{array}$ & $\begin{array}{c}14.7 \\
21.9 \%\end{array}$ & $\begin{array}{c}25.1 \\
65.0 \%\end{array}$ & $\begin{array}{c}8.9 \\
113.4 \%\end{array}$ \\
\hline Abortion rate (per 1000 women) & $\begin{array}{c}-8.1 \\
-38.7 \%\end{array}$ & $\begin{array}{l}-24.9 \\
-41.5 \%\end{array}$ & $\begin{array}{c}-24.4 \\
-34.5 \%\end{array}$ & $\begin{array}{c}-3.2 \\
-34.0 \%\end{array}$ \\
\hline Children at age 30 & $\begin{array}{l}-0.01 \\
-1.4 \%\end{array}$ & $\begin{array}{l}-0.02 \\
-3.6 \%\end{array}$ & $\begin{array}{c}-0.20 \\
-15.8 \%\end{array}$ & $\begin{array}{l}-0.10 \\
-4.0 \%\end{array}$ \\
\hline \multicolumn{5}{|c|}{ Lifetime outcomes } \\
\hline & Type 1 & Type 2 & Type 3 & Type 4 \\
\hline Children & $\begin{array}{c}-0.19 \\
-19.9 \%\end{array}$ & $\begin{array}{c}-0.13 \\
-18.2 \%\end{array}$ & $\begin{array}{c}-0.26 \\
-16.4 \%\end{array}$ & $\begin{array}{l}-0.13 \\
-3.9 \%\end{array}$ \\
\hline$\%$ College grad. or more & $\begin{array}{c}1.3 \\
1.7 \%\end{array}$ & $\begin{array}{c}1.0 \\
1.3 \%\end{array}$ & $\begin{array}{c}0.1 \\
26.1 \%\end{array}$ & $\begin{array}{c}0.0 \\
-\end{array}$ \\
\hline Schooling (years) & $\begin{array}{c}0.06 \\
0.3 \%\end{array}$ & $\begin{array}{c}0.01 \\
0.0 \%\end{array}$ & $\begin{array}{c}0.01 \\
0.0 \%\end{array}$ & $\begin{array}{c}0.00 \\
0.0 \%\end{array}$ \\
\hline Experience at age 30 & $\begin{array}{c}-21 \\
-0.1 \%\end{array}$ & $\begin{array}{c}-21 \\
-0.1 \%\end{array}$ & $\begin{array}{c}573 \\
3.3 \%\end{array}$ & $\begin{array}{c}107 \\
2.6 \%\end{array}$ \\
\hline Experience at age 65 & $\begin{array}{c}147 \\
0.2 \%\end{array}$ & $\begin{array}{c}83 \\
0.1 \%\end{array}$ & $\begin{array}{c}348 \\
0.5 \%\end{array}$ & $\begin{array}{c}356 \\
1.7 \%\end{array}$ \\
\hline Earnings & $\begin{array}{c}\$ 7,903 \\
0.6 \%\end{array}$ & $\begin{array}{c}\$ 1,923 \\
0.1 \%\end{array}$ & $\begin{array}{c}\$ 3,206 \\
0.4 \%\end{array}$ & $\begin{array}{c}\$ 4,230 \\
1.8 \%\end{array}$ \\
\hline
\end{tabular}


contraception and abortion. For instance, if abortion were banned and that ban were perfectly enforced, contraceptive use would increase by nearly 11 percentage points. As a result, only one out of every two abortions would be replaced by an additional birth. Less extreme restrictions on abortions exhibit similar effects in terms of this substitution pattern. Previous research has found that some abortion restrictions have effects on abortion rates without affecting birth rates, which suggests a large amount of adjustment in contraceptive effort as abortion costs rise (Levine et al., 1996). The results in this paper confirm and quantify these patterns. Moreover, I also find that providing free contraception would have strong effects on both contraceptive use and abortion decisions. This implies that women who are marginal in terms of the contraceptive decisions are also those with a relatively low cost of obtaining an abortion.

As a result of expanding mandatory counseling restrictions or closing all the providers in a county, abortion rates for women ages 18 to 30 would fall by $8 \%$ and $7 \%$, respectively. This means that in most cases - for more than $90 \%$ of the women who choose an abortion- these restrictions would simply increase the cost women face when obtaining an abortion. If all the providers in a given county were to close, $93 \%$ of women living in that county who would have had an abortion would travel to a different county to access abortion services. Among the small group of women for whom these restrictions would affect their abortion choices, a majority of these changes would result from the prevention of pregnancies through increased use of contraception, rather than a change in the abortion decision upon a pregnancy.

Notably, abortion restrictions have important effects on schooling and lifetime earnings, although only moderate effects on labor supply. If a ban on abortion were implemented and perfectly enforced, accumulated schooling after high school would decrease by $13 \%$ and lifetime earnings by $4.5 \%$ for women who would have otherwise had at least one abortion during their lifetime. Even though a perfectly enforced ban is an extreme version of restrictions on abortion access, these results show the strong impact that these restrictions have on women's human capital accumulation. 


\section{A Appendix I: Functional forms and distributional assumptions}

\section{A.1 Functional forms}

Preferences The flow utility function in equation (1) can be written as:

$$
U_{a}=C_{a}+U_{a}^{h p}+U_{a}^{h f}+U_{a}^{s}+U_{a}^{N}+U_{a}^{f}-\sum_{k=0}^{2} e_{a}^{k}-\xi a b_{a}
$$

Where:

$$
\begin{aligned}
U_{a}^{h p} & =h_{a}^{p}\left(\sum_{l=1}^{4} \alpha_{l}^{h p} 1\{\text { type }=l\}+\alpha_{5}^{h p} N^{*}+\alpha_{6}^{h p}\left(1-h_{a-1}^{p}-h_{a-1}^{f}\right)+\alpha_{7}^{h p} h_{a-1}^{f}\right)+\eta_{a}^{h p} \\
U_{a}^{h f} & =h_{a}^{f}\left(\sum_{l=1}^{4} \alpha_{l}^{h f} 1\{\text { type }=l\}+\alpha_{5}^{h f} N^{*}+\alpha_{6}^{h f}\left(1-h_{a-1}^{p}-h_{a-1}^{f}\right)+\alpha_{7}^{h f} h_{a-1}^{p}\right)+\eta_{a}^{h f} \\
U_{a}^{s} & =s_{a}\left(\sum_{l=1}^{4} \alpha_{l}^{s} 1\{\text { type }=l\}+\alpha_{5}^{s} N^{*}+\alpha_{6}^{s} h_{a}^{p}+\alpha_{7}^{s} h_{a}^{f}+\alpha_{8}^{s} a+\alpha_{9}^{s} 1\left\{S_{a}=15\right\}+\alpha_{10}^{s} s_{a-1}\right)+\eta_{a}^{s} \\
U_{a}^{N} & =\alpha_{1}^{N} N_{a}+\alpha_{2}^{N}\left(N_{a}^{5}\right)^{2}+\alpha_{3}^{N}\left(N_{a}^{17}\right)^{2}+\alpha_{4}^{N} n_{a} N_{a}^{5}+\alpha_{5}^{N} n_{a} N^{17}+\alpha_{6}^{N} N_{a}^{5} N_{a}^{17}+\alpha_{7}^{N} m_{a} N_{a}+\alpha_{8}^{N} c h_{a} N_{a} \\
U_{a}^{f} & =f_{a}\left(1-a b_{a}\right)\left(\alpha_{1}^{f} a+\alpha_{2}^{f} a^{2}+\alpha_{3}^{f} n_{a}+\alpha_{4}^{f} s_{a}+\alpha_{5}^{f} h_{a}^{p}+\alpha_{6}^{f} h_{a}^{f}+\alpha_{7}^{f} n_{a}\left(1-m_{a}-c h_{a}\right)+\alpha_{8}^{f} c h_{a}+\eta_{a}^{f}\right)
\end{aligned}
$$

And the birth control disutilities are:

$$
\begin{aligned}
& e_{a}^{0}=0+\nu_{a}^{0} \\
& e_{a}^{1}=\delta_{0}^{1}+\nu_{a}^{1} \\
& e_{a}^{2}=\delta_{0}^{2}+\delta_{1}^{2} N_{a}+\delta_{2}^{2}\{a<25\}+\delta_{3}^{2} a+\delta_{4}^{2} a^{2}+\delta_{5}^{2} c h_{a}+\delta_{6}^{2} m_{a}+\nu_{a}^{3}
\end{aligned}
$$

$C$ is consumption; $N$ indicates the total number of children under 18 , while $n, N^{5}$ and $N^{17}$ are the number of children in each age group; $s$ is an indicator for school (college/graduate school) attendance; $h^{p}$ and $h^{f}$ are the labor supply indicators; $m$ and $c h$ are the marital status indicators; $f$ denotes a pregnancy and $a b$ an abortion; ; and $-\xi$ is the idiosyncratic disutility of getting an abortion. Recall that I have not included a time constraint. The parameters in the utility function that multiply the interaction of any of the choices and $N^{*}$ are supposed to capture the disutility produced by spending time in that given choice instead of with the children. The function $N^{*}$ measures the children, for this purpose, in terms of the importance of time relative to a newborn:

$$
N^{*}=n_{a}+\gamma_{1} N_{a}^{5}+\gamma_{2} N_{a}^{17}
$$

Thus, $\alpha_{5}^{h p}$ is the disutility of the time not spent with a newborn due to part-time work, while $\gamma_{1}$ measures the time required for a child between 1 and 5 years of age, relative to the one for a newborn. 
Production function of pregnancies The probability that a pregnancy occurs is a function of the birth control choice, the level of sexual activity, and some of the state variables.

$$
P\left(f=1 \mid b c_{a}, S X_{a}, S_{a}, a\right)= \begin{cases}\Pi\left(b c_{a}, S X_{a}, S_{a}, a\right) & \text { for } b c_{a}=1,2 \\ 0 & \text { for } b c_{a}=3\end{cases}
$$

With $\Pi(\cdot)$ taking a logistic form :

$$
\Pi(\cdot)=\frac{\exp \left(Y_{a}^{f}\right)}{1+\exp \left(Y_{a}^{f}\right)}
$$

And:

$$
Y_{a}^{f}=\phi_{0}+\phi_{1} a+\phi_{2} a^{2}+1\left\{b c_{a}=2\right\}\left(\phi_{3}+\phi_{4} a+\phi_{5} S_{a}\right)+\sum_{x=2}^{3} \phi_{4+x} 1\left\{S X_{a}=x\right\}
$$

Wage Women's wages, as presented in section 3.4, are given by the product of the unit rental price of human capital $r^{o}$ for full-time or part-time jobs ( $o=f, p$, respectively) and the woman's accumulated human capital $\Lambda_{a}$ :

$$
w_{a}^{o}=r^{o} \Lambda_{a}\left(S_{a}, H_{a}, \text { type }, \varepsilon_{a}\right)
$$

The accumulated human capital at age $a, \Lambda_{a}$, is given by:

$$
\Lambda_{a}=\exp \left(\sum_{l=1}^{4} \beta_{l}^{w} 1\{\text { type }=l\}+\beta_{5}^{w} S_{a}+\beta_{6}^{w} S_{a}^{2}+\beta_{7}^{w} h_{a}+\beta_{8}^{w} H_{a}^{2}+\beta_{9}^{w} a+\varepsilon_{a}\right)
$$

The rental prices $r^{f}$ and $r^{p}$ cannot be identified separately from the all the type specific intercepts. I thus normalize: $r^{f}=1$.

Husband/partner earnings Earnings for the husband or partner are given by:

$$
\ln y_{a}^{h}=\beta_{0}^{h}+\beta_{1}^{h} a+\beta_{2}^{h} a^{2}+\varphi_{a}^{h}+\varepsilon_{a}^{h}
$$

At the beginning of a marriage/cohabitation spell, the "earnings potential" that characterizes the husband/partner, $\varphi_{a}^{h}$, is drawn from the normal distribution $N\left(\mu_{a}^{\varphi}(S\right.$, type $\left.), \sigma_{\varphi}^{2}\right)$, where the mean of the distribution is given by:

$$
\mu_{a}^{\varphi}=\sum_{l=1}^{4} \beta_{l}^{\varphi} 1\{\text { type }=l\}+\beta_{5}^{\varphi} S_{a}+\beta_{6}^{\varphi} S_{a}^{2}
$$

As with the wage function, all of the the type-specific means cannot be separately identified from $\beta_{0}^{h}$ and thus I normalize $\beta_{0}^{h}=0$.

Transition probabilities There are six other exogenous stochastic events in the model: initiating sexual life, the transition of marital status, the level of sexual activity, a pregnancy not ending in miscarriage, and the transition between types of locations.

For the sexual initiation hazard, I assume a simple logistic form:

$$
P\left(s i_{a}=1 \mid s i_{a-1}=0\right)=\frac{\exp \left(Y_{a}^{s i}\right)}{1+\exp \left(Y_{a}^{s i}\right)}
$$


With:

$$
Y_{a}^{s i}=\sum_{l=2}^{L} \psi_{l}^{s i} 1\{\text { type }=l\} \psi_{5}^{s i} a+\psi_{6}^{s i} a^{2}
$$

The distribution of probabilities over marital status is assumed to follow a logistic form, with a minor variation. For women who are either single or cohabiting in the current period, the probability distribution over the next period's marital status follows a multinomial logit:

$$
\begin{array}{r}
P\left(m_{a+1}=1 \mid m_{a}=0\right)=\frac{\exp \left(Y_{a}^{m}\right)}{1+\exp \left(Y_{a}^{m}\right)+\exp \left(Y_{a}^{c h}\right)} \\
P\left(c h_{a+1}=1 \mid m_{a}=0\right)=\frac{\exp \left(Y_{a}^{c h}\right)}{1+\exp \left(Y_{a}^{m}\right)+\exp \left(Y_{a}^{c h}\right)} \\
P\left(m_{a+1}=0, c h_{a+1}=0 \mid m_{a}=0\right)=\frac{1}{1+\exp \left(Y_{a}^{m}\right)+\exp \left(Y_{a}^{c h}\right)}
\end{array}
$$

For currently married woman, it follows a simple logit, as I assume that there are no transitions from marriage directly into cohabitation:

$$
\begin{array}{r}
P\left(m_{a+1}=1 \mid m_{a}=1\right)=\frac{\exp \left(Y_{a}^{m}\right)}{1+\exp \left(Y_{a}^{m}\right)} \\
P\left(c h_{a+1}=1 \mid m_{a}=1\right)=0 \\
P\left(m_{a+1}=0, c h_{a+1}=0 \mid m_{a}=1\right)=\frac{1}{1+\exp \left(Y_{a}^{m}\right)}
\end{array}
$$

With:

$$
\begin{aligned}
Y_{a}^{m}= & \sum_{l=1}^{L} 1\{\text { type }=l\}\left(\psi_{l}^{m}+\psi_{4+l}^{m} a+\psi_{9}^{m} a^{2}+\psi_{10}^{m} s_{a}+\psi_{11}^{m} S_{a}+\right. \\
& c h_{a}\left(\psi_{12}^{m}+\psi_{13}^{m} \operatorname{dur}(c h)_{a}+\psi_{14}^{m} S_{a}\right)+m_{a}\left(\psi_{15}^{m}+\psi_{16}^{m} d u r(m)_{a}+\psi_{17}^{m} S_{a}\right) \\
Y_{a}^{c h}= & \sum_{l=1}^{L} 1\{\text { type }=l\}\left(\psi_{l}^{c h}+\psi_{4+l}^{c h} a+\psi_{9}^{c h} a^{2}+\psi_{10}^{c h} s_{a}+\psi_{11}^{c h} S_{a}+\right. \\
& c h_{a}\left(\psi_{12}^{c h}+\psi_{13}^{c h} \operatorname{dur}(c h)_{a}+\psi_{14}^{c h} S_{a}\right)
\end{aligned}
$$

The level of sexual activity $S X_{a}$ falls in one of three possible categories, indexed by $x$. I model the probability of $S X_{a}=x$, for the different values of $x$, as an ordered logit:

$$
\begin{aligned}
& \operatorname{Pr}\left(S X_{a}=1\right)=\frac{1}{1+\exp \left(-Y_{a}^{S X}\right)} \\
& \operatorname{Pr}\left(S X_{a}=2\right)=\frac{1}{1+\exp \left(\psi_{1}^{S X}-Y_{a}^{S X}\right)}-\frac{1}{1+\exp \left(-Y_{a}^{S X}\right)} \\
& \operatorname{Pr}\left(S X_{a}=3\right)=1-\frac{1}{1+\exp \left(\psi_{1}^{S X}-Y_{a}^{S X}\right)}
\end{aligned}
$$

$Y_{a}$ is given by: 


$$
Y_{a}^{S X}=\psi_{0}^{S X}+\psi_{2} a+\psi_{3}^{S X} a^{2}+\psi_{4}^{S X} d m_{i, a}+\sum_{l=2}^{4} 1\left\{\text { type }_{a}=l\right\}\left(\psi_{(3+l)}^{S X}+\psi_{(6+l)}^{S X} d m_{a}\right)
$$

I make the assumption that the transition between the availability of a provider or not is independent from the transition of a state from not having mandatory counseling to imposing this kind of regulation. The transition for provider availability follows a first order Markov process with transition matrix:

$$
q^{l o c}=\left[\begin{array}{ll}
1-q_{0,1}^{l o c} & q_{0,1}^{l o c} \\
1-q_{1,1}^{l o c} & q_{1,1}^{l o c}
\end{array}\right]
$$

For women who live in a state where mandatory counseling has ever been imposed, the transition matrix is given by:

$$
q^{r e g}=\left[\begin{array}{cc}
1-q_{0,1}^{r e g} & q_{0,1}^{r e g} \\
0 & 1
\end{array}\right]
$$

Whereas for women who don't live in this type of state, I assume that they assign zero probability to the state ever imposing it.

Finally, the probability of a miscarriage occurring is simply given by $q^{m c}$.

Distribution of unobserved types and initial conditions The set of initial conditions includes religiosity $(\mathrm{rel})$, initial age $(\underline{\mathrm{a}})$, and a list of state variables at age at $\underline{a}$ : having a newborn $\left(n_{\underline{a}}\right)$, whether the woman has initiated her sexual life or not $\left(s i_{\underline{a}}\right)$, the type of location $\left(\right.$ regtype $\left._{\underline{a}}\right)$, and the lagged labor supply $\left(h_{\underline{a}-1}\right)$. The type of location can take one of four possible categories, representing the combinations of having a provider or not in county and whether the state ever is of the restrictive type (in the data, this means that the state is ever observed to impose mandatory counseling restrictions).

The distribution over unobserved types is assumed to depend on $\underline{a}, n_{\underline{a}}, s i_{\underline{a}}$, and regtype $\underline{a}_{\underline{a}}:$

$$
P\left(\text { type }=l \mid \underline{a}, n_{\underline{a}}, s i_{\underline{a}}, \text { regtype }_{\underline{a}}\right)=\frac{\exp \left(Y^{l}\right)}{\sum_{s=1}^{4} \exp \left(Y^{s}\right)}
$$

Where $Y^{1}=0$ and for $l>1$ :

$$
Y^{l}=\omega_{0}^{l}+\omega_{1}^{l} s \underline{a}_{\underline{a}}+\omega_{2}^{l} n_{\underline{a}}+\sum_{r=2}^{4} \omega_{1+r}^{l} 1\left\{\text { regtype }_{\underline{a}}\right\}+\omega_{6}^{l}(\underline{a}-18)
$$

\section{A.2 Distributional assumptions}

Psychic cost of abortion The abortion disutilities or psychic costs are distributed, conditional on type, as a $\log$-normal random variable with mean $\mu_{\xi}^{r e l, l}$ and variance $\sigma_{\xi}$, where $l$ refers to the unobserved type and rel to the religiosity category.

$$
\mu_{\xi}^{r e l, l}=\sum_{l=1}^{4} \zeta_{l} 1\{\text { type }=l\}+\zeta_{5} 1\{\text { rel }=2\}+\zeta_{6} 1\{r e l=3\}-\frac{\sigma_{\xi}}{2}
$$


The subtraction of $\frac{\sigma_{\xi}}{2}$ is a normalization that makes

$$
E(\xi \mid \text { type }=l, r e l=s)=\exp \left(\zeta_{l}+\zeta_{s+3} 1\{s \neq 1\}\right)
$$

Preference shocks I assume that the preference shocks for contraceptive methods are distributed according to:

$$
\nu_{i, a}^{k} \sim \operatorname{Gumbel}\left(0, \sigma_{\nu}\right)
$$

Thus, the differences in these shocks are distributed Extreme Value Type I (with scale parameter $\sigma_{\nu}$ ).

The preference shocks for all other choices are distributed multivariate normal with mean zero and symmetric variance-covariance matrix:

$$
\Sigma_{\eta}=\left(\begin{array}{cccc}
\sigma_{h p}^{2} & \sigma_{h p, h f} & \sigma_{h p, n} & \sigma_{h p, s} \\
& \sigma_{h f}^{2} & \sigma_{h f, n} & \sigma_{h f, s} \\
& & \sigma_{n}^{2} & \sigma_{n, s} \\
& & & \sigma_{s}^{2}
\end{array}\right)
$$

Because the utility is linear in consumption, there is no need to normalize one of the elements in $\Sigma_{\eta}$ to fix the scale.

Wage shocks The wage shock and the shock to the husband's earnings are each distributed i.i.d. normal, with mean zero and variances $\sigma_{w}^{2}$ and $\sigma_{y h}^{2}$, respectively.

\section{B Appendix II: Measurement error processes}

This section complements section 5.1 in the main text.

\section{B.1 Unbiased measurement error for discrete variables}

Suppose that we have a variable $v$ that can take one of $J$ possible values. Let $\tilde{v}$ be the observed realization of the variable and $v$ the true one under the model (simulated one in the context of this paper). What we want is to specify the measurement error probabilities $\pi_{j, k}=P(\tilde{v}=k \mid v=j)$ so that the measurement error process is unbiased:

$$
P(\tilde{v}=j)=P(v=j)
$$

Keane and Wolpin (2001) (KW) and Keane and Sauer (2010) (KS) use a specification for discrete variables that can take only 2 different values (in their case, the indicator variables for different choices). In that case, the measurement error rates are defined as:

$$
\begin{gathered}
\pi_{1,1}=E+(1-E) P_{1} \\
\pi_{1,0}=1-\pi_{1,1}=(1-E)\left(1-P_{1}\right) \\
\pi_{0,1}=\left(1-\pi_{1,1}\right) \frac{P_{1}}{\left(1-P_{1}\right)}=(1-E) P_{1} \\
\pi_{0,0}=1-\pi_{0,1}=E+(1-E) *\left(1-P_{1}\right)
\end{gathered}
$$


Where $P_{1}=P(v=1)$ and $E$ is a parameter to be estimated. This specification satisfies the unbiasedness restriction. It also satisfies the two conditions on the limit of these conditional probabilities as the $P_{1}$ goes to zero or 1 mentioned in KS:

$$
\begin{aligned}
& \lim _{P_{j} \rightarrow 1} \pi_{j, j}=1 \\
& \lim _{P_{j} \rightarrow 0} \pi_{j, j}=E
\end{aligned}
$$

This can be easily generalized to a multinomial setting. A multinomial specification includes more information than the binomial one used by KS and KW. The key difference comes from how these two specifications include "incorrect reports". As an example, take the case of labor supply that is reported as part-time when full-time is true. In $\mathrm{KS}$ and $\mathrm{KW}$, the contribution this event is treated as reporting no full-time when full-time is true. The multinomial specification includes information on how it is actually reported (reporting part-time when full-time is true) and that part-time might be a more or less frequent choice than not working.

Thus, for a variable $v$ that can take one of $J$ possible values, the $\pi_{j, k}$ 's can be written as:

$$
\pi_{j, k}=\left(1-E^{v}\right) P_{k}
$$

for $j \neq k$, and

$$
\pi j, j=E^{v}+\left(1-E^{v}\right) P_{j}
$$

$E^{v}$ is the measurement error parameter for variable $v$.

This specification satisfies the necessary conditions defined in KS, which in this case are:

1. $\sum_{j=1}^{J} P_{j} \pi_{j, k}=P_{k}$

2. $\lim _{P_{j} \rightarrow 1} \pi_{j, j}=1$

3. $\lim _{P_{j} \rightarrow 0} \pi_{j, j}=E^{v}$

4. $\lim _{P_{j} \rightarrow 1} \pi_{j, k}=0$ (This was automatically satisfied in the binomial case)

The first condition refers to unbiasedness (UB).

\section{B.2 Biased measurement error process for fertility outcomes}

The biased measurement error process for fertility outcomes was described in section 5.1. I summarize the key elements here to highlight the connection with the unbiased process just described and for the purpose of completeness.

As opposed to the unbiased case, the $\pi_{j, k}$ 's don't need to satisfy any restriction (in principle) in a biased specification. Although KS present a parametric specification that follows a logistic form as an example for the biased case, that assumption is not necessary. In the particular case of fertility outcomes of this paper, I have further assumed that the bias comes exclusively from the underreporting of abortions. Thus, for all the $\pi_{j, k}$ 's where $j \neq a b$, the specification is identical to the one of an unbiased case. This is what I referred to as nested unbiasedness in the main text.

Now, recall that $\rho$ denotes the ratio of reported to true abortion rates. $\pi_{a b, a b}$, the probability of truthfully reporting an abortion, can be written as (this is equation (15) in the main text):

$$
\pi_{a b, a b}=\rho-\frac{\pi_{n p, a b} P_{n p}+\pi_{m c, a b} P_{m c}+\pi_{b, a b} P_{b}}{P_{a b}}
$$


I use values for $\rho$ calculated using aggregate abortion rates, and thus $\pi_{a b, a b}$ becomes a function of other probabilities in this measurement error process and $\rho$. Using the specification for these other probabilities $\left(\pi_{j, a b}\right.$ 's) that comes from the nesting the biased process in an unbiased one, $\pi_{a b, a b}$ can be simplified to: ${ }^{36}$

$$
\pi_{a b, a b}=\rho-\left(1-E^{f e r}\right)\left(1-P_{a b}\right)
$$

Finally, as mentioned in section 5.1, I further assume that:

$$
\begin{aligned}
\pi_{a b, b} & =\left(1-E^{f e r}\right) P_{b} \\
\pi_{a b, m c} & =\lambda\left(1-\pi_{a b, a b}-\pi_{a b, b}\right) \\
\pi_{a b, n p} & =(1-\lambda)\left(1-\pi_{a b, a b}-\pi_{a b, b}\right)
\end{aligned}
$$

With $\lambda=1-q^{m c}$.

\section{B.3 Smoothing of $\rho$ and age}

As described in section 5.1, I assume that the biased measurement error process for fertility outcomes changes with age. This is necessary, as the measures of $\rho$ that I construct for different age groups are different: $47 \%$ for women between 20 and 24 years if age, and 33\% for women 25-29. Specifying the measurement error process to change according to these 5-year age groups would have the undesirable consequence of introducing a discontinuity in the measurement error process: the model will produce abortion rates that change smoothly with age but the measurement error process would "require" a strong and discontinuous jump between ages 24 and 25. To solve this, I assume that $\rho_{a}$ follows the following parametric form:

$$
\rho_{a}=\frac{\exp \left(\phi_{0}+\phi_{1} a+\phi_{2} a^{2}\right)}{1+\exp \left(\phi_{0}+\phi_{1} a+\phi_{2} a^{2}\right)}
$$

To estimate the parameters in this process I need at least two more measures for $\rho$ (for age groups) plus some assumptions. Luckily, as mentioned earlier, my estimates for $\rho$ match those of Jones and Kost (2007), who also have estimates for women $15-19$ and $30-34$. I use these, plus the assumption that the $\rho$ for a 5 -year age group is the same as the $\rho_{a}$ for one age in the age group, to estimate the parameters in the equation for $\rho_{a}$ above and produce a smoothed version of these ratios.

\section{B.4 Continuous variables}

Finally, for all continuous outcomes (wages, income), I will assume that these variables are measured with error in the data and that this measurement error $u$ is normally distributed:

$$
\begin{gathered}
\tilde{c v}=c v+u_{c v} \\
u_{c v} \sim N\left(0, \sigma_{e-c v}^{2}\right)
\end{gathered}
$$

For each continuous variable $c v$.

For women who have not initiated their sexual life at age $\underline{a}$, the measurement error for the age at sexual initiation $(\operatorname{age}(s i))$ is assumed to follow a latent process where:

\footnotetext{
${ }^{36}$ To ensure that $\pi_{a b, a b}>0$, the lower limit on $E$ fer is set accordingly. In an unbiased case $E$ only needs to be larger than 0.
} 


$$
a \tilde{g} e^{*}(s i) \sim N\left(\operatorname{age}(s i), \sigma_{s i}^{2}\right)
$$

Because the observed age a $a \tilde{g} e(s i)$ can only be an integer, a a $e(s i)=x$ if $a \tilde{g} e^{*}(s i) \in[x-0.5, x+0.5)$.

\section{Appendix III: Estimation and Parameter estimates}

\section{C.1 Likelihood function}

Some notation is needed before explicitly writing the likelihood function. First, let us divide the outcome variables that are used for estimation in three categories: discrete variables that are observed once $(\mathcal{X})$, discrete variables that may be observed in each period $(\mathcal{Y})$, and continuous variables that may be observed in each period $(\mathcal{Z})$ :

$$
\begin{aligned}
& \mathcal{X}=\left\{\underline{a}, n_{\underline{a}}, \text { si }_{\underline{a}}, \text { rel }, \text { regtype }_{\underline{a}}, \text { age }(\text { si })\right\} \\
& \mathcal{Y}=\{h, s, b c, \text { fer }, \text { loc }, \text { regul }, S X, M,\} \\
& \mathcal{Z}=\left\{w, y^{h}\right\}
\end{aligned}
$$

Where fer is a variable that summarizes the fertility outcomes for which the measurement error is assumed to be biased (abortions, miscarriages, pregnancies, births). All other variables have been defined earlier.

Now, let $q$ be a function that returns the conditional probability mass function for a pair of true and observed outcomes. For discrete variable $V$ that can take values in $\left\{v_{1}, v_{2}, \ldots, v_{K}\right\}, q$ is then defined as:

$$
q^{V}\left(v_{j} \mid v_{s}\right) \equiv \prod_{k=1}^{K} \prod_{r=1}^{K} P\left(\tilde{V}=v_{r} \mid V=v_{k}\right)^{1\left\{V_{r}=v_{j}\right\} 1\left\{v_{k}=v_{s}\right\}}
$$

With $1\{S\}$ being an indicator function taking the value of 1 is statement $S$ is true. Notice that if variable $V$ is not observed, $q=1$. Finally, let $f_{V}$ be the probability density function of the continuous measurement error of variable $V$ if variable $V$ is observed:

$$
f_{V}(a) \equiv p d f_{V}(a)^{1\{V \neq \emptyset\}}
$$

The simulated maximum algorithm that I use is based on the simulation of $D$ histories of outcomes variables under the model, given a parameter vector $\Theta$. The simulated maximum likelihood function is then (in $\log$ ): ${ }^{37}$

$$
L L(\tilde{\mathcal{X}}, \tilde{\mathcal{Y}}, \tilde{\mathcal{X}} \mid \Theta)=\sum_{i=1}^{N} \log \left\{\frac{1}{D} \sum_{d=1}^{D}\left[\prod_{X \in \mathcal{X}} q^{X}\left(\tilde{x}_{i} \mid x_{d}\right) \prod_{a=\tilde{a}_{i}}^{\bar{a}_{i}} \prod_{Y \in \mathcal{Y}} q_{a}^{Y}\left(\tilde{y}_{i, a} \mid y_{i, a}\right) \prod_{Z \in \mathcal{Z}} f_{Z}\left(\tilde{z}_{i, a}-z_{i, a}\right)\right]\right\}
$$

\footnotetext{
${ }^{37}$ With some abuse of notation, $L L(\tilde{\mathcal{X}}, \tilde{\mathcal{Y}}, \tilde{\mathcal{X}} \mid \Theta)$ refers to the observed data. Also, when defining functions $q$ and $f$, it is clear that the probability mass functions and probability density functions are not really defined for arguments that are not observed, as I have incorrectly implied to make this exposition shorter.
} 
Where $\bar{a}_{i}$ is the oldest age in which woman $i$ is observed in the data. The parameter vector $\Theta$ enters the likelihood function through the the "true" outcome variables which are simulated using the model at a given value of the parameter vector. I have not written this explicitly to save on notation.

\section{C.2 Calculation of standard errors}

The standard errors are estimated using the BHHH estimator (outer product of gradients). However, the likelihood function is not smooth. Thus, when calculating the scores, I perform the following steps:

1. For each element $\theta_{k}$ in $\Theta$, evaluate the likelihood function at $\hat{\Theta}+n \epsilon_{k}$, for $n \in\{-5,-4, \ldots, 4,5\}$.

2. Fit a second order polinomial with the evaluated points. This smooths out the change in $L L$ as you move $\Theta$ around the $k^{t h}$ element in a neighborhood of $\hat{\theta}_{k}$, the estimated value for that element.

3. Evaluate the derivative of the polynomial at $\hat{\theta}_{k}$ and use this as an approximation to the partial derivative of the likelihood function with respect to $\theta_{k}$ at $\hat{\theta}_{k}$.

\section{C.3 Parameter estimates}

Table 14: Parameter Estimates

\begin{tabular}{|c|c|c|c|c|c|c|c|c|c|c|}
\hline \multicolumn{11}{|l|}{ Utility } \\
\hline$\alpha_{1}^{h p}$ & $\alpha_{2}^{h p}$ & $\alpha_{3}^{h p}$ & $\alpha_{4}^{h p}$ & $\alpha_{5}^{h p}$ & $\alpha_{6}^{h p}$ & $\alpha_{7}^{h p}$ & & & & \\
\hline-2.8584 & -2.4156 & -3.2899 & -5.5217 & -1.7060 & -0.9010 & -0.8309 & & & & \\
\hline$(0.0004)$ & $(0.0007)$ & $(0.0006)$ & $(0.0007)$ & $(0.0002)$ & $(0.0002)$ & $(0.0002)$ & & & & \\
\hline$\alpha_{1}^{h f}$ & $\alpha_{2}^{h f}$ & $\alpha_{3}^{h f}$ & $\alpha_{4}^{h f}$ & $\alpha_{5}^{h f}$ & $\alpha_{6}^{h f}$ & $\alpha_{7}^{h f}$ & & & & \\
\hline-14.8875 & -10.2491 & -10.3076 & -20.8051 & -2.2816 & -0.7135 & -0.4826 & & & & \\
\hline$(0.0012)$ & $(0.0009)$ & $(0.0009)$ & $(0.0117)$ & $(0.0004)$ & $(0.0002)$ & $(0.0001)$ & & & & \\
\hline$\alpha_{1}^{s}+T^{\text {coll }}$ & $\alpha_{2}^{s}+T^{\text {coll }}$ & $\alpha_{3}^{s}+T^{\text {coll }}$ & $\alpha_{4}^{s}+T^{\text {coll }}$ & $\alpha_{5}^{s}$ & $\alpha_{6}^{s}$ & $\alpha_{7}^{s}$ & $\alpha_{8}^{s}$ & $\alpha_{9}^{s}$ & $\alpha_{10}^{s}$ & \\
\hline-15.2435 & -14.6453 & -19.9374 & -18.0760 & -3.3500 & -6.2099 & -12.9109 & -1.4704 & 4.9750 & -0.8737 & \\
\hline$(0.0018)$ & $(0.0018)$ & $(0.0091)$ & $(0.6636)$ & $(0.0009)$ & $(0.0005)$ & $(0.0016)$ & $(0.0002)$ & $(0.0063)$ & $(0.0002)$ & \\
\hline$\alpha_{1}^{N}$ & $\alpha_{2}^{N}$ & $\alpha_{3}^{N}$ & $\alpha_{4}^{N}$ & $\alpha_{5}^{N}$ & $\alpha_{6}^{N}$ & $\alpha_{7}^{N}$ & $\alpha_{8}^{N}$ & & & \\
\hline 0.3605 & -0.0890 & -0.0870 & 0.0946 & 0.0749 & -0.0087 & 1.7812 & 0.5996 & & & \\
\hline$(0.0017)$ & $(0.0000)$ & $(0.0000)$ & $(0.0001)$ & $(0.0002)$ & $(0.0000)$ & $(0.0002)$ & $(0.0001)$ & & & \\
\hline$\alpha_{1}^{f}$ & $\alpha_{2}^{f}$ & $\alpha_{2}^{f}$ & $\alpha_{2}^{f}$ & $\alpha_{2}^{f}$ & $\alpha_{2}^{f}$ & $\alpha_{2}^{f}$ & $\alpha_{2}^{f}$ & & & \\
\hline 0.0235 & -0.0296 & 0.0050 & -0.4550 & -1.3235 & -0.4831 & -1.8123 & -0.3138 & & & \\
\hline$(0.0000)$ & $(0.0000)$ & (0.0004) & $(0.0016)$ & $(0.0005)$ & $(0.0007)$ & $(0.0032)$ & $(0.0007)$ & & & \\
\hline$\delta_{0}^{1}$ & $\delta_{1}^{2}$ & $\delta_{2}^{2}$ & $\delta_{3}^{2}$ & $\delta_{3}^{2}$ & $\delta_{4}^{2}$ & $\delta_{5}^{2}$ & $\delta_{6}^{2}$ & $\gamma_{1}$ & $\gamma_{2}$ & \\
\hline 0.3008 & 2.1756 & -1.7089 & 5.1432 & -0.2558 & 0.0198 & -0.0007 & -0.6162 & 0.8460 & 0.2090 & \\
\hline$(0.0000)$ & $(0.0117)$ & $(0.0014)$ & $(0.0800)$ & $(0.0002)$ & $(0.0000)$ & $*$ & $(0.0028)$ & $(0.0000)$ & $(0.0000)$ & \\
\hline$\zeta_{1}$ & $\zeta_{2}$ & $\zeta_{3}$ & $\zeta_{4}$ & $\zeta_{5}$ & $\zeta_{6}$ & $\sigma_{\xi}$ & & & & \\
\hline 2.3837 & 1.8346 & 3.4583 & 2.1475 & 0.3384 & 0.3552 & 1.1972 & & & & \\
\hline$(0.0007)$ & $(0.0005)$ & $(0.0006)$ & $(0.0021)$ & $(0.0001)$ & $(0.0001)$ & $(0.0001)$ & & & & \\
\hline \multicolumn{11}{|c|}{ Budget constraint } \\
\hline$T^{\text {grad }}-T^{\text {coll }}$ & $\tau^{h}$ & $\kappa_{0}$ & $\kappa_{1}$ & $\kappa_{2}$ & $c_{1}^{b c}$ & $c_{2}^{b c}$ & & & & \\
\hline-8.3316 & -0.1136 & 0.4700 & 0.3335 & 0.3263 & 0.3600 & 4.0000 & & & & \\
\hline$(0.0024)$ & $(0.0000)$ & - & $(0.0004)$ & $(0.0004)$ & - & - & & & & \\
\hline \multicolumn{11}{|l|}{ Wage } \\
\hline$r^{f t}$ & $r_{p t}$ & $\beta_{1}^{w}$ & $\beta_{2}^{w}$ & $\beta_{3}^{w}$ & $\beta_{4}^{w}$ & $\beta_{5}^{w}$ & $\beta_{6}^{w}$ & $\beta_{7}^{w}$ & $\beta_{8}^{w}$ & $\beta_{9}^{w}$ \\
\hline 1.0000 & -0.2219 & 1.3419 & -0.0833 & 0.0175 & -0.1645 & 0.0652 & -0.0001 & 0.0160 & -0.0002 & 0.0332 \\
\hline & $(0.0000)$ & $(0.0000)$ & $(0.0000)$ & $(0.0000)$ & $(0.0000)$ & $(0.0000)$ & $(0.0000)$ & $(0.0000)$ & $(0.0000)$ & $(0.0000)$ \\
\hline
\end{tabular}


Table 14 :Parameter Estimates (continued)

\begin{tabular}{|c|c|c|c|c|c|c|c|c|c|}
\hline \multicolumn{10}{|c|}{ Husband's income } \\
\hline$\beta_{0}^{h}$ & $\beta_{1}^{h}$ & $\beta_{2}^{h}$ & $\beta_{1}^{\varphi}$ & $\beta_{2}^{\varphi}$ & $\beta_{3}^{\varphi}$ & $\beta_{4}^{\varphi}$ & $\beta_{5}^{\varphi}$ & $\beta_{6}^{\varphi}$ & \\
\hline 0.0000 & 0.1761 & -0.0051 & 1.9851 & 0.0596 & 0.2130 & 0.0408 & 0.0467 & -0.0014 & \\
\hline- & $(0.0000)$ & $(0.0000)$ & $(0.0000)$ & $(0.0000)$ & $(0.0000)$ & $(0.0010)$ & $(0.0000)$ & $(0.0000)$ & \\
\hline \multicolumn{10}{|c|}{ Pregnancies } \\
\hline$\phi_{0}$ & $\phi_{1}$ & $\phi_{2}$ & $\phi_{3}$ & $\phi_{4}$ & $\phi_{5}$ & $\phi_{6}$ & $\phi_{7}$ & & \\
\hline-1.2985 & 0.0203 & 0.0017 & -0.0042 & -1.3396 & -0.2140 & 0.1997 & 0.1883 & 0.197 & \\
\hline$(0.0000)$ & $(0.0000)$ & $(0.0000)$ & $(0.0000)$ & $(0.0001)$ & $(0.0000)$ & $(0.0000)$ & $(0.0010)$ & 0.000 & \\
\hline \multicolumn{10}{|l|}{$\Sigma_{e t a}$} \\
\hline$\sigma_{h p}^{2}$ & $\sigma_{h p, h f}$ & $\sigma_{h p, n}$ & $\sigma_{h p, s}$ & $\sigma_{h f}^{2}$ & $\sigma_{h f, n}$ & $\sigma_{h f, s}$ & $\sigma_{n}^{2}$ & $\sigma_{n, s}$ & $\sigma_{s}^{2}$ \\
\hline 1.3550 & 0.7012 & 1.0302 & -0.3949 & -0.5153 & 0.6274 & -0.1582 & -0.4513 & -0.8474 & 1.8905 \\
\hline$(0.0001)$ & $(0.0001)$ & $(0.0001)$ & $(0.0002)$ & $(0.0001)$ & $(0.0002)$ & $(0.0000)$ & $(0.0001)$ & $(0.0001)$ & $(0.0002)$ \\
\hline \multicolumn{10}{|c|}{ Transition probabilities } \\
\hline$\psi_{1}^{c h}$ & $\psi_{2}^{c h}$ & $\psi_{3}^{c h}$ & $\psi_{4}^{c h}$ & $\psi_{5}^{c h}$ & $\psi_{6}^{c h}$ & $\psi_{7}^{c h}$ & $\psi_{8}^{c h}$ & $\psi_{9}^{c h}$ & $\psi_{10}^{c h}$ \\
\hline-2.5300 & -2.1549 & -2.7134 & -2.0200 & 0.0793 & 0.1492 & 0.0710 & 0.0803 & -0.0065 & -0.5920 \\
\hline$(0.0001)$ & $(0.0001)$ & $(0.0000)$ & $(0.0000)$ & $(0.0000)$ & $(0.0000)$ & $(0.0000)$ & $(0.0000)$ & $(0.0000)$ & $(0.0002)$ \\
\hline$\psi_{11}^{c h}$ & $\psi_{12}^{c h}$ & $\psi_{13}^{c h}$ & $\psi_{14}^{c h}$ & & & & & & \\
\hline-0.0425 & 3.7291 & 0.1640 & 0.1115 & & & & & & \\
\hline$(0.0000)$ & $(0.0000)$ & $(0.0002)$ & $(0.0001)$ & & & & & & \\
\hline$\psi_{1}^{m}$ & $\psi_{2}^{m}$ & $\psi_{3}^{m}$ & $\psi_{4}^{m}$ & $\psi_{5}^{m}$ & $\psi_{6}^{m}$ & $\psi_{7}^{m}$ & $\psi_{8}^{m}$ & $\psi_{9}^{m}$ & $\psi_{10}^{m}$ \\
\hline-3.3050 & -3.1000 & -3.2384 & -2.7143 & 0.0036 & 0.0061 & -0.0058 & 0.0130 & 0.0009 & -0.4008 \\
\hline$(0.0001)$ & $(0.0001)$ & $(0.0000)$ & $(0.0000)$ & $(0.0000)$ & $(0.0000)$ & $(0.0000)$ & $(0.0000)$ & $(0.0000)$ & $(0.0002)$ \\
\hline$\psi_{11}^{m}$ & $\psi_{12}^{m}$ & $\psi_{13}^{m}$ & $\psi_{14}^{m}$ & $\psi_{15}^{m}$ & $\psi_{16}^{m}$ & $\psi_{17}^{m}$ & & & \\
\hline 0.0382 & 1.8679 & 0.1470 & 0.0420 & 5.9456 & 0.3805 & 0.0591 & & & \\
\hline$(0.0000)$ & $(0.0000)$ & $(0.0003)$ & $(0.0000)$ & $(0.0000)$ & $(0.0000)$ & $(0.0000)$ & & & \\
\hline$\psi_{1}^{s i}$ & $\psi_{2}^{s i}$ & $\psi_{3}^{s i}$ & $\psi_{4}^{s i}$ & $\psi_{5}^{s i}$ & $\psi_{6}^{s i}$ & & & & \\
\hline-0.3620 & -0.0221 & -0.0387 & -0.0111 & -0.0822 & -0.0021 & & & & \\
\hline$(0.0000)$ & $(0.0018)$ & $(0.0002)$ & $(0.0002)$ & $(0.0515)$ & $(0.0177)$ & & & & \\
\hline$\psi_{1}^{S X}$ & $\psi_{2}^{S X}$ & $\psi_{3}^{S X}$ & $\psi_{4}^{S X}$ & $\psi_{5}^{S X}$ & $\psi_{6}^{S X}$ & $\psi_{7}^{S X}$ & $\psi_{8}^{S X}$ & $\psi_{9}^{S X}$ & \\
\hline-3.1650 & 2.5237 & 0.0440 & -0.0120 & 6.0000 & -0.3626 & -6.4095 & 1.9522 & 0.2885 & \\
\hline$(0.0000)$ & $(0.0000)$ & $(0.0000)$ & $(0.0025)$ & $(0.0002)$ & $(0.0036)$ & $(0.0007)$ & $(0.0002)$ & $(0.0001)$ & \\
\hline$q_{0,1}^{l o c}$ & $q_{1,1}^{l o c}$ & $q_{0,1}^{r e g}$ & $q^{m c}$ & & & & & & \\
\hline 0.02462 & 0.97107 & 0.09634 & 0.89643 & & & & & & \\
\hline$(0.0000)$ & $(0.0000)$ & $(0.0000)$ & $(0.0001)$ & & & & & & \\
\hline \multicolumn{10}{|c|}{ Other distributional parameters } \\
\hline$\sigma_{w}$ & $\sigma_{h}$ & $\sigma_{\varphi}$ & $\sigma_{n u}$ & & & & & & \\
\hline 0.0499 & 0.0067 & 0.4078 & 0.0512 & & & & & & \\
\hline$(0.0000)$ & $(0.0000)$ & $(0.0000)$ & $(0.0000)$ & & & & & & \\
\hline \multicolumn{10}{|c|}{ Type probabilities } \\
\hline$\omega_{1}^{2}$ & $\omega_{2}^{2}$ & $\omega_{3}^{2}$ & $\omega_{4}^{2}$ & $\omega_{5}^{2}$ & $\omega_{6}^{2}$ & & & & \\
\hline 0.0483 & -0.0289 & -0.1572 & 0.3873 & 0.8086 & 0.1010 & & & & \\
\hline$(0.0465)$ & $(0.0443)$ & $(0.0764)$ & $(0.0366)$ & $(0.0363)$ & $(0.0500)$ & & & & \\
\hline$\omega_{1}^{3}$ & $\omega_{2}^{3}$ & $\omega_{3}^{3}$ & $\omega_{4}^{3}$ & $\omega_{5}^{3}$ & $\omega_{6}^{3}$ & & & & \\
\hline 0.0152 & -0.0005 & 0.0077 & 0.8846 & 1.2746 & 0.9194 & & & & \\
\hline$(0.0377)$ & $(0.0361)$ & $(0.0576)$ & $(0.0262)$ & $(0.0278)$ & $(0.0325)$ & & & & \\
\hline$\omega_{1}^{4}$ & $\omega_{2}^{4}$ & $\omega_{3}^{4}$ & $\omega_{4}^{4}$ & $\omega_{5}^{4}$ & $\omega_{6}^{4}$ & & & & \\
\hline-0.5223 & -0.0004 & 0.4597 & 0.1803 & 0.8958 & -0.0054 & & & & \\
\hline$(0.0421)$ & $(0.0371)$ & $(0.0590)$ & $(0.0333)$ & $(0.0316)$ & $(0.0405)$ & & & & \\
\hline
\end{tabular}


Table 14 :Parameter Estimates (continued)

\begin{tabular}{|c|c|c|c|c|c|c|c|c|c|}
\hline \multicolumn{10}{|c|}{ Measurement error } \\
\hline$E_{f e r}$ & $E_{h}$ & $E_{s}$ & $E_{s i_{\underline{a}}}$ & $E_{r e g_{a}}$ & $E_{l o c}$ & $E_{r e g}$ & $E_{b c}$ & $E_{m}$ & $E_{S X}$ \\
\hline 0.8500 & 0.3502 & 0.4148 & 0.2000 & 0.8961 & 0.8535 & 0.9407 & 0.4994 & 0.5857 & 0.5180 \\
\hline$(0.0000)$ & $(0.0781)$ & $(0.0005)$ & $(0.0000)$ & $(0.0000)$ & $(0.0000)$ & $(0.0000)$ & $(0.0000)$ & $(0.0002)$ & $(0.0011)$ \\
\hline$E_{\underline{a}}$ & $E_{n_{\underline{a}}}$ & $E_{r e l}$ & $\sigma_{e-w}$ & $\sigma_{e-y h}$ & $\sigma_{e-s i}$ & & & & \\
\hline 0.2000 & 0.4000 & 0.2848 & 0.3298 & 0.3223 & 2.6736 & & & & \\
\hline$(0.0000)$ & $(0.0000)$ & 0.0000 & $(0.0007)$ & 0.0000 & $(0.0001)$ & & & & \\
\hline
\end{tabular}




\section{References}

Adda, J., C. Dustmann, and K. Stevens (2012). The career cost of children. EUI Working Paper ECO2012/01.

Akerlof, G. A., J. L. Yellen, and M. L. Katz (1996). An analysis of out-of-wedlock childbearing in the united states. The Quarterly Journal of Economics 111(2), 277-317.

Althaus, F. A. and S. K. Henshaw (1994). The effects of mandatory delay laws on abortion patients and providers. Family Planning Perspectives 26(5), 228-233.

Angrist, J. D. and W. N. Evans (1998). Children and their parents' labor supply: Evidence from exogenous variation in family size. American Economic Review 88(3), 450-477.

Arcidiacono, P., A. Khwaja, and L. Ouyang (2012). Habit persistence and teen sex: Could increased access to contraception have unintended consequences for teen pregnancies? Journal of Business and Economic Statistics 30(2), 312-325.

Beauchamp, A. (2012). Regulation, imperfect competition, and the U.S. abortion market. Working Paper.

Carro, J. M. and P. Mira (2006). A dynamic model of contraceptive choice of spanish couples. Journal of Applied Econometrics 21, 955-980.

Colman, S. and T. Joyce (2009). Minors behavioral responses to parental involvement laws: Delaying abortion until age 18. Perspectives on Sexual and Reproductive Health 41(2), 119-126.

Cook, P. J., A. M. Parnell, M. J. Moore, and D. Pagnini (1999). The effects of short-term variation in abortion funding on pregnancy outcomes. Journal of Health Economics 18(2), 241-257.

Delavande, A. (2008). Pill, patch, or shot? subjective expectations and birth control choice. Internationl Economic Review 49(3), 999-1042.

Dennis, A., S. K. Henshaw, T. J. Joyce, L. B. Finer, and K. Blanchard (2009). The impact of laws requiring parental involvement for abortion: A literature review.

Francesconi, M. (2002). A joint dynamic model of fertility and work of married women. Journal of Labor Economics 20(2), 336-380.

Gayle, G.-L. and R. A. Miller (2006). Life-cycle fertility and human capital accumulation. Tepper School of Business, Carneggie Mellon University. Working Papers 2004-E16.

Grossman, D., S. Baum, L. Fuentes, K. White, K. Hopkins, A. Stevenson, and J. E. Potter (2014). Change in abortion services after implementation of a restrictive law in texas. Contraception 90, 496-501.

Haussman, J. A., J. Abrevaya, and F. M. Scott-Morton (1998). Missclassification of the dependant variable in a discrete-response setting. Journal of Econometrics 87, 239-269.

Heckman, J. J. and B. Singer (1984). A method for minimizing the impact of distributional assumptions in econometric models for duration data. Econometrica 52(2), 271-320.

Henshaw, S. K., T. J. Joyce, A. Dennis, L. B. Finer, and K. Blanchard (2009). Restrictions on medicaid funding for abortions: A literature review. 
Hotz, V. J. and R. A. Miller (1988). An empirical analysis of life cycle fertility and female labor supply. Econometrica 56(1), 91-118.

Hotz, V. J. and R. A. Miller (1993). Conditional choice probabilities and the estimation of dynamic models. The Review of Economic Studies 60(3), 497-529.

Jones, R. K., L. B. Finer, and S. Singh (2010). Characteristics of u.s. abortion patients, 2008. Technical report, Guttmacher Institute.

Jones, R. K. and J. Jerman (2014). Abortion incidence and service availability in the united states, 2008. Perspectives on Sexual and Reproductive Health 43(1).

Jones, R. K. and M. L. Kavanaugh (2011). Changes in abortion rates between 2000 and 2008 and lifetime incidence of abortion. Obstetrics and Gynecology 117(6), 1358-1366.

Jones, R. K. and K. Kooistra (2011). Abortion incidence and access to services in the united states, 2011. Perspectives on Sexual and Reproductive Health 46(1), 41-50.

Jones, R. K. and K. Kost (2007). Underreporting of induced ans spontaneous abortions in the united states: An analysis of the 2002 national survey of family growth. Studies in Family Planning 38(3), 187-197.

Joyce, T., S. K. Henshaw, and J. D. Skatrud (1997). The impact of mississippis mandatory delay law on abortions and births. Journal of the American Medical Association 278(8), 653-658.

Joyce, T. and R. Kaestner (2000). The impact of mississippis mandatory delay law on the timing of abortion. Family Planning Perspectives 32(1), 4-13.

Joyce, T., R. Kaestner, and S. Colman (2006). Changes in abortions and births and the texas parental notification law. The New England Journal of Medicine 354(10), 1031-1038.

Joyce, T. J., S. K. Henshaw, A. Dennis, L. B. Finer, and K. Blanchard (2009). The impact of state mandatory counseling and waiting period laws on abortion: A literature review.

Joyce, T. J., R. Tan, and Y. Zhang (2012). Back to the future? abortion before and after roe. Nber Working Paper 18338.

Kane, T. J. and D. Staiger (1996). Teen motherhood and abortion access. The Quarterly Journal of Economics 111, 467-506.

Keane, M. P. and R. M. Sauer (2009). Classification error in dynamic discrete choice models: Implications for female behavior. Econometrica 77(3), 975-991.

Keane, M. P. and R. M. Sauer (2010). A computationally practical simulation estimation algorithm for dynamic panel data models with unoserved endogenous state variables. International Economic Review 51(4), 925-958.

Keane, M. P. and K. I. Wolpin (2001). The effect of parental transfers and borrowing constraints on educational attainment. International Economic Review 42(4), 1051-1103.

Keane, M. P. and K. I. Wolpin (2007). Exploring the usefulness of a nonrandom holdout sample for model validation: Welfare effects on female behavior. International Economic Review 48(4), 1351-1378. 
Keane, M. P. and K. I. Wolpin (2010). The role of labor and marriage markets, preference heterogeneity, and the welfare system in the life cycle decisions of black, hispanic, and white women. International Economic Review 51(3), 851-892.

Kearney, M. and P. B. Levine (2009). Subsidized contraceptive, fertility, and sexual behavior. The Review of Economics and Statistics 91(1), 137-151.

Kennes, J. and J. Knowles (2013). Can technological change account for the sexual revolution? School of Economics and Management, University of Aarhus. Economics Working Papers 2013-07.

Kocharkov, G. (2012). Abortions and inequality. Working Paper.

Levine, P. B. (2003). Parental involvement laws and fertility behavior. Journal of Health Economics 22(5), $861-878$.

Levine, P. B., A. B. Trainor, and D. J. Zimmerman (1996). The effect of medicaid abortion funding restrictions on abortions, pregnancies and births. Journal of Health Economics 15, 555-578.

Moffit, R. (1984). Profiles of fertility, labour supply and wages of married women: A complete life-cyclemodel. The Review of Economic Studies 51(2), 263-278.

Morgan, S. P. and A. M. Parnell (2002). Effects on pregnancy outcomes of changes in the north carolina state abortion fund. Population Research and Policy Review 21(4), 319-338.

Mosher, W. D. and J. Jones (2010). Use of contraception in the united states: 1982-2008. Technical report, Center for Disease Control and Prevention, U.S. Departmen of Health and Human Services. Vital and Health Statistics. Series 23. no. 29.

Pazol, K., S. B. Zane, W. Y. Parker, L. R. Hall, C. Berg, and D. Cook (2011). Abortion surveilance - united states, 2008. Technical report, Center for Disease Control and Prevention, U.S. Department of Health and Human Services.

Planned Parenthood. Birth control. http://www.plannedparenthood.org/health-info/birth-control [Last accessed 11/07/2014].

Rosenszweig, M. and K. I. Wolpin (1980). Life cycle labor supply and fertility: Causal inferences from household models. Journal of Political Economy 88, 328-348.

Secura, G. M., T. Madden, C. McNicholas, J. Mullersman, C. M. Buckel, Q. Zhao, and J. F. Peipert (2014). Provision of no-cost, long-acting contraception and teenage pregnancy. The New England Journal of Medicine 371(14), 1316-1323.

Ventura, S. J., J. C. Abma, and W. D. Mosher (2009). Estimated pregnancy rates for the united states 1990-2005: An update. Technical report, Center for Disease Control and Prevention, U.S. Department of Health and Human Services. 